Revista lus et Praxis, Año 19, № 2, 2013, pp. 207 - 250

ISSN 0717 - 2877

Universidad de Talca - Facultad de Ciencias Jurídicas y Sociales

"Concurso de normas y concurso de acciones en el

Derecho Procesal Civil chileno"

Sophía Romero Rodríguez

\title{
CONCURSO DE NORMAS Y \\ CONCURSO DE ACCIONES EN EL DERECHO PROCESAL CIVIL CHILENO*
}

CONCURRENCE OF NORMS AND CONCURRENCE

of actions in the chilean Civil Procedural LaW

SOPHÍA Romero Rodríguez*

\begin{abstract}
RESUMEN
El artículo pretende explicar el fenómeno del concurso o concurrencia y las principales causas que lo originan, diferenciando el concurso de normas del concurso de acciones. Posteriormente, se analizan las consecuencias que se producen en el proceso a raíz de esta diferenciación, aplicando las soluciones planteadas a casos existentes en el ordenamiento procesal civil chileno.
\end{abstract}

ABSTRACT

This article intends to explain the concurrence phenomenon and the main causes that originate it, stating the difference between concurrence of norms and concurrence of actions. The consequences produced in the process due to this differentiation are analyzed subsequently, applying solutions considered in existing cases from the Chilean civil procedural legal system.

PalabRas Clave

Concurrencia, Causa petendi, Objeto del proceso

KEYWORDS

Concurrence, Causa petendi (cause of action), Procedural object

\footnotetext{
* Trabajo recibido el 30 de agosto y aprobado el 09 de octubre de 2013.

Abreviaturas utilizadas. CPRCH Constitución Política de la República de Chile; CPC Código de Procedimiento Civil; CC Código Civil; LPDC Ley de protección de los derechos del consumidor; LOBGM Ley orgánica de bases generales del Medio Ambiente; ICA Ilustrísima Corte de Apelaciones; LCD Ley de Competencia Desleal; LPInd Ley de Propiedad Industrial; LPInt Ley de Propiedad Intelectual; DLLC Decreto Ley sobre Libre Competencia; LOCBGAE Ley Orgánica Constitucional de Bases Generales de la Administración del Estado; RDJ Revista de Derecho y Jurisprudencia.

** Licenciada en Ciencias Jurídicas por la Universidad Católica del Norte (Chile), Abogada, Profesora de Derecho Procesal de la Facultad de Ciencias Jurídicas de la Universidad Católica del Norte (Chile), Alumna regular del Programa de Doctorado en Derecho de la Facultad de Derecho de la Universidad de los Andes (Chile), Becaria CONICYT para estudios de Doctorado en Chile (Desde 2011). Correo electrónico: sromeror@ucn.cl, sromero@miuandes.cl.
} 


\section{INTRODUCCIÓN}

La creación por parte del legislador de mecanismos de protección de los derechos e intereses privados genera en la actualidad que exista una multiplicidad de vías procesales para la obtención de un mismo beneficio jurídico.

Lo que en principio constituye una mejoría en las condiciones de los justiciables ante la eventual solicitud de tutela de sus derechos, se convierte en un problema a la hora de presentar y substanciar los diversos procedimientos ante distintos órganos jurisdiccionales, ya que el legislador en pocas oportunidades ha previsto de qué forma se solucionarán las consecuencias procesales derivadas de la concurrencia normativa, las que en muchos casos tienen también repercusiones en la esfera de los derechos materiales.

De este modo, sin que exista en la mayoría de los casos una respuesta expresa del legislador para la solución de este fenómeno llamado concurrencia, es posible articular algunas propuestas para solucionar estos problemas mediante la aplicación adecuada de instituciones procesales actualmente vigentes en nuestro ordenamiento, como son la litispendencia, la cosa juzgada en sus efectos positivo y negativo, la acumulación de autos, entre otros.

En el presente trabajo explicaremos en qué consiste la concurrencia como fenómeno común en las ciencias jurídicas y, posteriormente, desarrollaremos algunas posibles causas del concurso. Luego estableceremos el status quaestionis tanto en la doctrina y legislación nacionales como en los autores más significativos de la doctrina alemana, italiana y española, con el objeto de dar luces para diferenciar el concurso de acciones del de normas.

Por último, analizaremos las consecuencias que en el proceso se desencadenan producto de la diferencia entre los dos tipos de concursos, y cómo lo anterior tiene repercusiones en la aplicación de institutos procesales a lo largo de todo el proceso: al inicio con la configuración de la acción en la demanda, durante su substanciación con la excepción de litispendencia y el incidente de acumulación de autos; y, finalmente, respecto de la excepción de cosa juzgada, siempre aplicando nuestra legislación procesal civil y considerando la jurisprudencia de nuestros tribunales de justicia.

\section{La Concurrencia normativa y sus Causas}

\section{Concepto}

Existe un concurso o concurrencia en el caso en que los supuestos de hecho de varias normas jurídicas pueden corresponderse plena o parcialmente, de tal modo que el mismo hecho sea comprendido por todos ellos ${ }^{1}$.

\footnotetext{
${ }^{1}$ Larenz, Karl, Metodología de la ciencia del Derecho, Ariel, Barcelona, 2001, p. 260.
} 
Siguiendo el concepto anterior, una primera situación de concurrencia puede generarse cuando ambas normas contemplen idénticas consecuencias jurídicas, caso en el cual el efecto está doblemente fundado en la ley. En esta misma hipótesis, puede ocurrir que existan dos normas que puedan ser aplicadas alternativamente, esto es, que la aplicación de una suponga la exclusión de la otra, pero antes de esa aplicación, ambas sean pertinentes².

Una segunda situación podría ser la eventual aplicación de ambas consecuencias jurídicas, partiendo de la base que las dos son distintas y compatibles entre sí, esto es, que no se excluyen recíprocamente, lo que se denomina "concurrencia acumulativa" ${ }^{\prime 3}$.

En tercer lugar, la aplicación de ambas normas con consecuencias jurídicas diversas e incompatibles, genera la necesidad de determinar qué norma se aplica y cuál no, encontrándonos ante un conflicto normativo ${ }^{4}$.

En este último caso debido a la ausencia, en la mayoría de los casos, de normas que expresamente regulen la eficacia normativa concurrencial, la doctrina ha creado diversos principios para determinar qué norma debe primar. En primer lugar, el factor jerárquico es relevante, ya que cualquier norma que suponga una infracción a una norma superior, debiera ser considerada como inaplicable en el caso concreto; en segundo lugar, el factor temporal, ya que la ley más moderna deroga tácitamente a la anterior; y, por último, el factor de la especialidad, el que requiere de un análisis adicional, ya que dependiendo de si la ley especial complementa, modifica o sustituye a la general en cuanto a la consecuencia jurídica derivada de su aplicación, puede suponer la pertinencia de ambas normas o desplazar la aplicación de la ley general, ya que la hipótesis contraria generaría la inaplicación total de la norma especial.

Además, la doctrina penal ha creado los principios de subsidiariedad, consunción y alternatividad ${ }^{5}$ para resolver los concursos relativos a tipos penales, y también se distingue entre aquel concurso propio e impropio, siendo el primero aquel en que surgen varios mecanismos legales para obtener el mismo beneficio jurídico; e impropio, cuando estos mecanismos se consideran distintos por fundarse en pretensiones diversas ${ }^{6}$.

Todo lo señalado hasta aquí, se refiere al denominado concurso de normas o de leyes, esto es, a la posibilidad de diversa calificación jurídica de unos mismos

\footnotetext{
2 Barros Bourie, Enrique, Tratado de responsabilidad extracontractual, Editorial Jurídica de Chile, Santiago, 2009, p. 1056.

${ }^{3}$ LARENZ, Metodología, cit. nota n. 1, p. 263.

${ }^{4}$ Barros, Tratado, cit. nota n. 2, p. 1055.

${ }_{5}^{5}$ Matus Acuña, Jean Pierre, El concurso aparente de leyes, Ediciones Jurídicas de Santiago, Santiago, 2008, pp. 35-44.

${ }^{6}$ BarRos, Tratado, cit. nota n. 2, p. 1054.
} 
hechos ${ }^{7}$. En cambio, el concurso de acciones ocurre cuando en base a unos mismos hechos, el demandante puede configurar una petición, delimitando su acción de forma distinta ${ }^{8}$. Como veremos más adelante, la diversidad del fenómeno imposibilita aplicar los mismos criterios de solución en ambos tipos de concurso.

\section{Causas}

\section{a) Soluciones al concurso en el proceso histórico}

A nuestro juicio, el fenómeno de la concurrencia de normas y de acciones es un problema derivado de la escisión producida entre los conceptos de derecho subjetivo y del de pretensión y acción.

En el proceso civil moderno configurado como mecanismo heterocompositivo de aplicación del Derecho objetivo -esencialmente compuesto por leyes en los sistemas de Derecho codificado-, los particulares afirman la titularidad de derechos e intereses privados considerados como dignos de protección por el ordenamiento objetivo, titularidad que será enjuiciada en el proceso mediante la dictación de la sentencia definitiva. De este modo, sólo la afirmación de esa titularidad constituye la pretensión y no el derecho o interés jurídico-material, el que se separa completamente ${ }^{9}$.

Por tanto, la afirmación de unos mismos hechos generadores de un derecho o interés pueden fundamentar más de una petición a un órgano jurisdiccional, o recibir amparo por parte de más de una norma jurídica.

Sin embargo, en el Derecho romano el concepto de derecho subjetivo no estaba delineado de manera tan separada respecto del Derecho objetivo, ya que para designar a ambos se utilizaba el concepto de $i u s^{10}$. De este modo, se ha concluido que para los romanos no existían derechos subjetivos sino más bien acciones ${ }^{11}$ que otorgaban un mecanismo de protección, partiendo del análisis de casos concretos y no de problemas abstractos ${ }^{12}$. Más aún, para los romanos,

\footnotetext{
7 Berzosa Francos, María Victoria, Demanda, "causa petendi", y objeto del proceso, El Almendro, Córdoba, 1984, p. 58.

${ }^{8}$ Berzosa, Demanda, cit. nota n. 7, p. 58.

${ }^{9}$ Para una síntesis de las teorías que explican la naturaleza jurídica de la acción, confróntese MonTero Aroca, Juan y otros, Derecho jurisdiccional I, Parte General, Tirant lo Blanch, Valencia, 2007, pp. 241253.

${ }^{10}$ Murga, José Luis, Derecho romano clásico. II. El Proceso, Secretariado de Publicaciones Universidad de Zaragoza, Zaragoza, 1989, p. 15.

11 Guzmán Brito, Alejandro, "Historia de la denominación del derecho-facultad como subjetivo", Revista de Estudios Histórico-Jurídicos, NºXV, 2003, pp. 409.

${ }^{12}$ MeGías, José, "El derecho subjetivo en el Derecho romano", Revista de Estudios Histórico-Jurídicos, No XXV, 2003, En: http://www.scielo.cl/scielo.php?script=sci_arttext\&pid=S0716-5455203002500002\&lng=es\&nrm=iso \&tlng=es [visitado el 12/04/2012].
} 
la acción era el derecho a perseguir en juicio lo debido, siguiendo la definición de $\mathrm{CELSO}^{13}$, confundiéndose de este modo la acción con el ius.

Adicionalmente, tanto en los procedimientos formulario y de acciones de la ley, cuando se invocaba una acción y se verificaba el contrato de litiscontestatio, éste generaba la imposibilidad de iniciar con posterioridad nuevos procesos invocando acciones concurrentes ${ }^{14}$. "Así, pues, por derecho clásico, tanto si entre dos personas concurrían dos o más acciones, cuando si las mismas concurrían entre varias personas del lado activo o pasivo, el solo ejercicio de una de estas acciones extinguía también todas las acciones concurrentes", lo que se ha denominado eficacia consumativa de la litiscontestatio ${ }^{15}$.

En otros términos, se ha señalado que el efecto de la litiscontestatio no consiste propiamente en consumir la acción que preexiste, sino la exclusión de toda acción ulterior sobre el mismo objeto debido a la extinción de la obligación que subyace a la acción ${ }^{16}$.

De este modo, en el Derecho romano este problema de concurrencia se solucionaba mediante el efecto consumativo o excluyente o, si se quiere, del pacto suscrito entre las partes con el objeto de someterse a la potestad del iudex.

Sin embargo, en la Edad Media, con el objeto liberar el proceso de trámites innecesarios y formalismos inútiles, se potencia la sumarización del solemnis ordo iudiciarius, haciendo desaparecer el efecto consumativo de la litiscontestatio, situación que se manifiesta en la legislación italiana y en las Partidas ${ }^{17}$.

En la actualidad, desaparecido este efecto consumativo y en donde el concepto relevante es el de derechos subjetivos y no ya el de acción ${ }^{18}$, la forma de limitar la posibilidad de procesos con un mismo objeto en la mayoría de los casos no viene dada por el legislador. Es por ello que estimamos que efectuando un análisis de los hechos jurídicamente relevantes y de las peticiones efectuadas se puede acotar la posibilidad de iniciar un nuevo proceso con objeto idéntico o limitar sus efectos por identidad parcial.

\footnotetext{
${ }^{13}$ D. 44,7, 51 (Celso 3).

${ }^{14}$ D. 50, 17, 43 (Ulpiano 28 ed.).

${ }^{15}$ LieBMAn, Tullio Enrico, "Acciones concurrentes", en Eficacia y autoridad de la sentencia y otros estudios sobre la cosa juzgada, EDIAR, Buenos Aires, 1946, 244-245 pp.

${ }^{16}$ WINDSCHeID, Bernhard, "La 'actio' del Derecho civil romano desde el punto de vista del Derecho actual", en Polémica sobre la "actio", EJEA, Buenos Aires, 1974, pp. 75 y ss.

${ }^{17}$ FAIRÉn GuILléN, Víctor, "La 'litis contestatio' y sus consecuencias: una perspectiva histórica del proceso", en Estudios de Derecho procesal, Editorial Revista de Derecho Privado, Madrid, 1955, p. 18; p. 24.

18 "Para la conciencia jurídica actual viene primero el derecho, la acción después; el derecho es lo generador, la acción lo generado. El derecho asigna a cada individuo la esfera de señorío en la cual su voluntad es ley para los demás; si dentro de esa esfera el individuo no es reconocido, puede presentar su queja, su reclamación, al Estado, custodio del derecho, y éste le ayuda a obtener lo que es suyo. El ordenamiento jurídico es el ordenamiento de los derechos". WINDSCHEID, "La 'actio', cit. nota n. 16, p. 8.
} 


\section{b) Codificación y descodificación}

En la década de 1970, Guzmán constataba una realidad que no difiere esencialmente de la actual: "(...) el derecho de los códigos se ha visto desmesuradamente rebasado por la legislación especial (...)"19.

Nuestra legislación procesal civil se unifica y fija por primera vez con la dictación del $\mathrm{CPC}^{20}$, el que conforme al mensaje enviado por, el entonces Presidente de la República, don Jorge Montt Álvarez tenía por objeto dar respuesta a la necesidad de uniformar las reglas de tramitación diseminadas en leyes numerosas y no pocas veces contradictorias ${ }^{21}$.

La elaboración de éste y los otros códigos aún vigentes en nuestro Derecho son fruto de la codificación, movimiento derivado de la llustración iniciado en el siglo XVIII en Europa, que a nivel jurídico pretendía el otorgamiento de certeza a los particulares de la titularidad de ciertos derechos subjetivos mediante la dictación de un cuerpo único de leyes -habitualmente escrito-que tuviera vigencia para todos los habitantes de un territorio determinado, sin hacer diferencias personales ni territoriales, poniéndose fin a una situación previa de anarquía y pluralidad de fuentes e instituciones ${ }^{22}$, enmarcándose en un concepto doctrinal más amplio, denominado fijación del Derecho ${ }^{23}$.

Sin embargo, a más de 100 años de la vigencia del CPC, el panorama que motivó su dictación se repite. Por ejemplo, las normas procesales aplicables en materia de Derecho de Familia que contenía el CPC, fueron derogadas por las contenidas en las Leyes de Matrimonio Civil ( $\left.N^{\circ} 19.947\right)$ y de Tribunales de Familia ( $N^{\circ} 19.968$ ); existen multiplicidad de juicios ejecutivos especiales que no siguen las normas del Libro III del CPC, salvo supletoriamente, dispersos en las leyes de cobranza previsional, ley general de bancos, por ejemplo; el procedimiento de aplicación general o juicio ordinario del Libro II no es aplicable a la tramitación efectuada ante juzgados de Policía Local, los que tienen también una ley especial; las normas sobre tramitación de juicios de arrendamiento sólo se aplican en la medida que no sea pertinente la Ley de Arrendamiento de Predio

\footnotetext{
${ }^{19}$ Guzmán Brito, Alejandro, La fijación del Derecho. Contribución al estudio de su concepto y de sus clases y condiciones, Ediciones Universitarias de Valparaíso, Valparaíso, 1977, p. 11.

${ }^{20}$ Nos referimos en este punto a la codificación relativa a procedimientos, ya que a nivel procesal orgánico existen codificaciones anteriores. Confróntese Bravo LiRA, Bernardino, "Los comienzos de la codificación en Chile: la codificación procesal", Revista Chilena de Historia del Derecho, No 9, 1983, pp. 191-210.

${ }^{21}$ Mensaje LeY № 1.552, Aprueba el nuevo Código de Procedimiento Civil, Diario Oficial, 30 de agosto de 1902.

22 González Vergara, Paulina, "Codificación y técnica legislativa", Revista Chilena de Derecho, vol. 25, No 4, 1998, pp. 876-879.

${ }^{23}$ GuZmán, La fijación, cit. nota n. 19, 128 pp.
} 
urbano o rústico (Nº 18.101 y D.L. No 993/1975 del Ministerio de Agricultura, respectivamente); el procedimiento sumario se aplica siempre que no existan normas diversas de tramitación en otros cuerpos legales, cuestión que cabe en materia de aguas y minas, por nombrar algunos casos.

Por tanto, habiendo partido desde la codificación, en la actualidad estamos en presencia del fenómeno inverso, el de la descodificación ${ }^{24}$, el que se funda en la necesidad de dar respuesta a la protección de intereses de carácter social, diversos de los amparados con los códigos decimonónicos de corte netamente individual, que requieren de instrumentos menos rígidos como son las leyes especiales $^{25}$.

De esta forma, la técnica legislativa cambia dirigiéndose desde los códigos hacia las leyes especiales, asumiendo la ley actual características de concreción y de individualidad: respuesta a específicos y determinados problemas ${ }^{26}$.

En este trance, la descodificación ha generado la huida desde los códigos procesales hacia la creación de estatutos y leyes especiales que disponen procedimientos y acciones especiales ${ }^{27}$, hace surgir estatutos paralelos que han generado situaciones como la poca claridad legal para la determinación del cauce procesal adecuado para la obtención de la tutela judicia ${ }^{28}$. La idea original de nuestro legislador procesal civil, manifestada en el artículo final del CPC, que derogó todas las disposiciones legales vigentes sobre las materias que éste trataba, era precisamente que todos los procesos fueran tramitados conforme sus normas -tanto el procedimiento ordinario como los especiales regulados en el libro III-, pretensión que ha sido a lo largo del siglo XX olvidada por la proliferación de procesos y tribunales especiales en leyes especiales diversas del $\mathrm{CPC}^{29}$.

\section{c) Deficiente técnica legislativa}

El concepto de concurso, como ya hemos dicho, parte de la base de la existencia de dos normas eventualmente aplicables a una misma situación de hecho

\footnotetext{
${ }^{24}$ Este concepto fue acuñado por el profesor Natalino Irti a partir del año 1978, y se encuentra explicado en un conjunto de trabajos publicados en la obra L'etá della decodificazione, Giuffrè, Milano, 1999, 220 pp. Existe traducción al español, La edad de la descodificación, Bosch, Barcelona, 1992, 214 pp.

${ }^{25}$ IRTI, La edad, cit. nota n. 24, p. 24.

${ }^{26}$ IRTI, La edad, cit. nota n. 24, p. 26.

${ }^{27}$ Catalogando como descodificación el fenómeno sufrido por nuestro Derecho procesal, confróntese Vargas Pavez, Macarena, "Reflexiones en torno a los alcances del fenómeno descodificador en el proceso civil", Revista Chilena de Derecho Privado, № 17, 2011, pp. 9-26.

${ }^{28}$ Romero Seguel, Alejandro, "La adecuación del procedimiento en materia de derecho indígena", Revista Chilena de Derecho, vol. 39, № 3, 2012, p. 821.

${ }^{29}$ Romero Seguel, Alejandro, La cosa juzgada en el proceso civil chileno. Doctrina y jurisprudencia, Editorial Jurídica de Chile, Santiago, 2002, pp. 33-34; pp. 123-124.
} 
concreta, lo que en una primera aproximación supone que el ordenamiento jurídico contemple para un mismo caso dos respuestas, que para no contrariar la idea sistémica del Derecho deben ser al menos compatibles.

En la realidad, la existencia de estas normas no supone en muchos casos una respuesta intencionada de nuestro legislador, sino más bien un defecto de técnica legislativa causado, entre otras razones, por presiones sociales que persiguen reivindicar mecanismos de tutela a los ciudadanos, en consideración a situaciones especiales o derechamente a un descuido derivado de la informalidad práctica que se produce dentro del proceso legislativo ${ }^{30}$.

Sumado el fenómeno de descodificación, y del análisis de muchas disposiciones legales, concluimos que el legislador olvida que una vez publicada la ley, ésta se insertará dentro del ordenamiento jurídico vigente, debiendo coexistir y conectarse con otras normas de superior o igual rango para que pueda desplegar eficazmente su contenido normativo ${ }^{31}$, sin que debieran existir duplicidades e incompatibilidades en la regulación.

Toda nueva ley debiese considerar cláusulas de derogación y de modificación del Derecho vigente para regular la incidencia de la nueva normativa sobre el ordenamiento jurídico. De este modo, muchos de los problemas de interpretación, integración y aplicación de las normas serían resueltos de manera más sencilla.

Resulta exigible desde la técnica legislativa, ante la compatibilidad de la aplicación de la nueva ley y de la antigua ley, establecer expresamente la derogación de la norma antigua ${ }^{32}$ con el objeto de evitar problemas de interpretación y aplicación de las normas jurídicas.

No existiendo este tipo de normas que regulen la eficacia de las distintas normas que temporal o espacialmente entren en conflicto, y manteniéndose ambas vigentes, la deficiente técnica del legislador constituye una de las causas del concurso.

\section{d) Autonomía de disciplinas jurídicas y convergencia entre regulaciones}

No sólo la creación y dispersión de nuevas normas y la deficiente técnica utilizada por el legislador contribuye a este fenómeno.

La creciente incorporación de nuevas normas al ordenamiento jurídico es sinónimo de que la regulación decimonónica no siempre da una respuesta ade-

\footnotetext{
${ }^{30}$ Cano Campos, Tomás, "Non bis in ídem, prevalencia de la vía penal y teoría de los concursos en el Derecho administrativo sancionador", Revista de Administración Pública, № 156, 2001, p. 194.

${ }^{31}$ Martín CASALS, Miguel, "Preámbulo y disposiciones directivas", en La forma de las leyes. Diez estudios de técnica legislativa, Bosch, Barcelona, 1986, p. 71.

32 Viver I PI-Sunyer, Carles, "La parte final de las leyes", en La forma de las leyes. Diez estudios de técnica legislativa, Bosch, Barcelona, 1986, pp. 176-177.
} 
cuada a las problemáticas de hoy. No es más que un síntoma de la inadaptación del Derecho a las necesidades presentes, a la incapacidad de los mecanismos jurídicos de que disponemos para solucionar los problemas actuales ${ }^{33}$.

Lo anterior, supone la necesidad del jurista de adaptarse al nuevo objeto de estudio, que en muchos casos puede suponer la creación de una nueva disciplina, debido a que las nuevas normas se apartan en su raíz -mediante la extracción de principios y reglas diversas- de las que fueron sus antecesoras.

Por ejemplo, del Derecho civil han nacido el Derecho del trabajo, el Derecho de familia, el Derecho del consumo, que constituyen nuevas disciplinas por basarse en principios jurídicos diversos de aquellos en que se estructuran las disciplinas de las cuales se apartaron e independizaron.

Partiendo de un conjunto de normas jurídicas vigentes, debemos establecer la existencia de un conjunto de instituciones y principios propios, que sean capaces de sustentarse por sí solos, estableciéndose de ese modo una matriz disciplinar ${ }^{34}$ para quienes forman parte de una comunidad científica determinada.

Sin embargo, una disciplina jurídica que se independiza de su matriz mantiene ciertos principios y reglas comunes, que implican que parcialmente la disciplina matriz y la disciplina filial comparten ciertos objetos.

Lo anterior, manifestado en el fenómeno concurrencial, explica que unos mismos hechos sean objeto de más de dos normas jurídicas y puedan ser amparados desde más de una perspectiva constituyéndose como objeto de dos o más acciones, siendo atención de más de una disciplina jurídica que aboga por la aplicación de sus propios principios para la solución de un mismo caso en detrimento de la solución propuesta por otra disciplina.

Por ejemplo, en nuestra legislación los concursos se crean habitualmente por la existencia de un sistema de protección de derechos de carácter general consagrado en algún cuerpo codificador, por ejemplo, el régimen de responsabilidad civil contractual del CC, y una ley que consagra un régimen especial en donde caben sólo una parte de las hipótesis que se pueden subsumir en el régimen general ${ }^{35}$, por ejemplo, el de la LPDC.

En estos casos, la doctrina civilista impondrá la aplicación de los principios que regulan la disciplina; en cambio, el Derecho del Consumo, más proteccionista en relación con los derechos del consumidor tratará de aplicar sus

\footnotetext{
${ }^{33}$ González Navarro, Francisco, Derecho administrativo español, EUNSA, Pamplona, 1995, p. 460.

34 "La matriz disciplinar es algo así como el punto primordial en que se concentran todas las teorías, conceptos, y leyes con que opera la comunidad científica de que se trate". González, Derecho administrativo, cit. nota n. 32, p. 483.

${ }^{35}$ Como origen del concurso en razón de esta misma causa, confróntese Ormazábal SÁnchez, Guillermo, lura novit curia. La vinculación del juez a la calificación jurídica de la demanda, Marcial Pons, Madrid, 2007, p. 99.
} 
principios en la solución de un asunto concreto, sustrayendo el análisis más general al caso. En este sentido, nos preguntamos si atendida la existencia de un concurso de normas en el caso descrito en donde el juez puede optar por aplicar la norma jurídica que estime pertinente al caso, podrá hacerlo cuando por cuestiones de competencia material se encuentra inhibido de hacerlo. Sin duda que está habilitado para aplicar el principio de especialidad en la solución del concurso normativo, sin embargo, ¿qué ocurre si por criterios de atribución competencial, si aplica la norma especial deviene en incompetente?

\section{e) Multiplicidad de tribunales especiales fuera del Poder Judicial}

Un fenómeno que, a nuestro juicio, repercute en la forma de configurar el sistema de acciones en nuestro Derecho es la existencia de órganos jurisdiccionales competentes para el conocimiento de acciones concurrentes que se encuentran fuera de la orgánica del Poder Judicial.

Entendemos la competencia como presupuesto procesal, ya que la tutela de los intereses y derechos subjetivos debe ser concedida por un órgano jurisdiccional que actúe en procesos en que la ley haya determinado, en virtud de ciertos criterios, dentro de su esfera de atribución, sin que sea posible configurar una relación procesal válida sin que el órgano que conocerá de la acción deducida cuente con este atributo ${ }^{36}$.

Desde la época romana se presentaba un problema común a nuestra época, el de competencias concurrentes sobre una misma materia, población o lugar ${ }^{37}$. Ello, se recrudece en nuestro sistema jurídico, debido a la proliferación de tribunales especiales para el conocimiento de tutelas especializadas en razón del elemento materia ${ }^{38}$.

En la actualidad, en virtud del principio de unidad jurisdiccional los órganos que ejercen jurisdicción dentro un territorio estatal determinado deben formar parte de un único poder del Estado y estar regulados por un único y común estatuto orgánico -el COT chileno-.

Sin embargo, en nuestro ordenamiento debido a la configuración que el constituyente de 1980 ha dado a la potestad jurisdiccional en el artículo 76 y

\footnotetext{
${ }^{36}$ En este sentido, en Chile Confróntese Romero Seguel, Alejandro, Curso de Derecho procesal civil. Los presupuestos procesales relativos al órgano jurisdiccional, Editorial Jurídica de Chile, Santiago, t. II, 2009, pp. 27 y ss.

${ }^{37}$ Robles Reyes, Juan, La competencia jurisdiccional y judicial en Roma, Servicio de Publicaciones de la Universidad de Murcia, Murcia, 2003, p. 9.

${ }^{38}$ A nivel contencioso-administrativo, para un análisis exhaustivo de este fenómeno, Confróntese FerRADA Bórquez, Juan Carlos, "Los tribunales que ejercen la justicia administrativa en el Derecho chileno", en Litigación Pública, Colección de Estudios de Derecho Público, Abeledo Perrot, Thompson Reuters, Santiago, 2011, pp. 119-150; particularmente pp. 133-144.
} 
la interpretación que el TC ha efectuado de esta norma, cualquier órgano constituido por ley como tribunal ejerce potestad jurisdiccional ${ }^{39}$. Lo anterior ha avalado a nuestro legislador en la creación de múltiples tribunales especiales fuera del Poder Judicial, unos autónomos y otros dentro de los órganos de la Administración del Estado.

Sólo por vía ejemplar, contamos con un Tribunal de Defensa de la Libre Competencia, tribunales ambientales, Tribunal de Propiedad Industrial, Tribunal de la Contratación Pública, tribunales tributarios y aduaneros; ello, sin considerar la proliferación de la atribución de "jurisdicción" de las Superintendencias y Subsecretarías, que constituyen sede contencioso-administrativo especial en muchas materias como Telecomunicaciones, Servicios Sanitarios, entre otros ${ }^{40}$.

Más allá de las discrepancias dogmáticas que se puedan señalar respecto de la configuración que efectúa nuestro legislador limitando o restringiendo el control que deben realizar los órganos jurisdiccionales de la actuaciones administrativas, y desde el análisis de la concurrencia, en muchos casos, estos órganos especiales conocen de unos hechos que pueden ser constitutivos de varias acciones o pueden ser subsumidos en más de una norma jurídica, pudiendo ser conocidas éstas ante diferentes tribunales, también especial u ordinario.

Por ejemplo, un hecho constitutivo de competencia desleal también puede serlo de atentado a la libre competencia, por lo que el hecho puede ser competencia de un juzgado de letras y también del Tribunal de la Libre Competencia. ¿Qué efectos produce en un proceso la sentencia dictada en el otro? ¿Se pueden iniciar ambos procesos de manera conjunta?

De este modo, resulta una primera dificultad al justiciable determinar cuál es la vía idónea para la obtención de la tutela que solicita, so pena de si yerra, eventualmente no pueda iniciar un nuevo proceso si la sentencia dictada en el primero produce el efecto de cosa juzgada en el segundo.

\footnotetext{
39 "La función jurisdiccional es genérica y omnicomprensiva respecto de todos aquellos órganos que resuelven conflictos que afectan bienes y derechos de las personas, aunque no sean propiamente "tribunales" e incluso no formen parte del Poder Judicial, sin perjuicio de que en definitiva se encuentren siempre sujetos a la superintendencia disciplinaria de la Corte Suprema". Salinas con Servicio de Impuestos Internos, Tribunal Constitucional, requerimiento de inaplicabilidad por inconstitucionalidad, 6 de septiembre de 2007, Rol № 616, c. 17. En: http://www.tribunalconstitucional.cl/wp/expedientes [visitado el 29/07/2013]. Otras sentencias que declaran la posibilidad que un órgano administrativo ejerza función jurisdiccional, confróntese Selume con Servicio de Impuestos Internos, Tribunal Constitucional, requerimiento de inaplicabilidad por inconstitucionalidad, 30 de agosto de 2006 , Rol № 472 , c. 15; Ibáñez y otros, Tribunal Constitucional, Requerimiento de inconstitucionalidad, 8 de abril de 2002, Rol No 346, c. 43.

${ }^{40}$ Lara Arroyo, José Luis, "Algunas reflexiones sobre el contencioso administrativo en Chile", en Litigación Pública, Colección Estudios de Derecho Público, LegalPublishing, Abeledo Perrot, Thompson Reuters, Santiago, 2011, pp. 76-77.
} 
Como hemos señalado, la inexistencia en nuestro Derecho del efecto consumativo o excluyente en las hipótesis de acciones concurrentes, y la imposibilidad en este caso de acumular los procesos ${ }^{41}$, genera varios problemas de índole procesal derivados del fenómeno en estudio, los que analizaremos en los siguientes apartados.

\section{Sobre EL CONCURSO DE NORMAS Y DE ACCIONES}

\section{Estado de la cuestión}

Como cuestión primera, haremos referencia a las normas y el análisis que la doctrina y la jurisprudencia chilenas han efectuado de este fenómeno. Posteriormente, ilustraremos esta investigación con las aportaciones que han realizado los autores más relevantes de la doctrina procesal alemana, española e italiana sobre la concurrencia.

Nos limitamos en esta investigación al concurso dentro de los sistemas de Derecho continental.

\section{a) En el ordenamiento jurídico chileno}

En nuestro Derecho civil y procesal civil no existen normas que aludan expresamente a la concurrencia. El Código Penal trata esta institución a propósito de los concursos de delitos (artículos 74 y 75), aplicando para su solución los principios de especialidad, consunción, subsidiariedad y alternatividad ${ }^{42}$.

De manera tangencial, podemos decir que las regulaciones relativas a la acumulación de autos y de acciones del CPC también son manifestaciones que parten del supuesto de acciones concurrentes en nuestro Derecho. En el caso de la acumulación inicial, se permite que las acciones sean compatibles o incompatibles ${ }^{43}$; y respecto de la acumulación sobrevenida, el legislador nada señala. A nuestro juicio, y del análisis de las disposiciones contenidas en el artículo 92 y siguientes del CPC, el único requisito que nuestro legislador indica para esta hipótesis de acumulación es que los procesos o acciones a acumular posean conexiones objetivas o subjetivas.

\footnotetext{
${ }^{41}$ Conforme el artículo 95 del Código de Procedimiento Civil, para que pueda proceder la acumulación, los juicios se deben encontrar sometidos a una misma clase de procedimiento, cuestión que no ocurre en el ejemplo (el primero, conforme las normas del juicio sumario y el segundo, un procedimiento especial similar a la vista en segunda instancia del proceso civil).

${ }^{42}$ Sobre estos principios en la doctrina penal chilena Confróntese EtCheVERRY Orthustegur, Alfredo, El concurso aparente de leyes penales, Editorial Jurídica de Chile, Santiago, S/A, 108 pp.; más modernamente, Matus, El concurso, cit. nota n. 5, 430 pp.

${ }^{43}$ Artículo 17 del CPC.
} 
A nivel sustantivo, la doctrina civil ha tratado el denominado "cúmulo de responsabilidades", aludiendo a la posibilidad de que un mismo hecho pueda constituir un supuesto de responsabilidad civil contractual y extracontractual ${ }^{44}$. Sin embargo, a pesar de la referencia al cúmulo o a la concurrencia, sólo los análisis más modernos respecto del tema tratan de diferenciar si este fenómeno concurrencial es de normas o de acciones ${ }^{45}$.

Siguiendo a Domínguez ${ }^{46}$ y Corral $^{47}$, pueden establecerse en la doctrina y jurisprudencia nacionales tres posiciones. La teoría de la no acumulación, absorción o incompatibilidad siendo la tesis tradicional, que parte de la existencia de un contrato, debiendo primar este régimen por sobre el extracontractual; la teoría del cúmulo opcional o concurso de acciones, que reconoce la existencia de dos acciones, pudiendo la víctima optar por el régimen de responsabilidad que le resulte más beneficioso, y la teoría del concurso de normas, en donde la acción es una sola, debiendo fundamentarse la demanda en las normas que se estimen pertinentes sin perjuicio de la interpretación judicial.

La doctrina civilista tradicional rechaza la hipótesis del cúmulo de responsabilidades, estableciendo que el régimen contractual es especial respecto del extracontractual, que será aplicable siempre que no exista una relación jurídica previa entre las partes, por tanto, la víctima del daño no tiene posibilidad de optar por el régimen de responsabilidad que le resulte más beneficioso ${ }^{48}$.

Sin embargo, en la actualidad, y esencialmente en base a los pronunciamientos efectuados por los tribunales superiores de justicia, se considera permitido por el ordenamiento la eventual opción del justiciable para impetrar la pretensión resarcitoria.

Más modernamente, BARROS señala que tratándose de un concurso propio (de normas), la acción resarcitoria es una, pero se puede fundar en dos o más

\footnotetext{
${ }^{44}$ Ello en atención a que en Chile el Código Civil establece un sistema dual de responsabilidad civil. A favor de un sistema unitario, YZQUIERDo TOLSADA, Mariano, Sistema de responsabilidad civil contractual y extracontractual, Dykinson, Madrid, 2001, pp. 82 y ss.

${ }^{45}$ A tonso quien al parecer manifiesta su posición por el concurso de acciones en su vertiente de absorción. Confróntese Alonso Traviesa, María Teresa, El problema de la concurrencia de responsabilidades, LegalPublishing, Fundación Fueyo, Santiago, 2007, pp. 526 y ss. Sin tomar una posición al respecto, Pérez Bravo, Carlos, "Concurrencia de responsabilidades", Ars Boni et Aequi, № 4, 2008, pp. 114 y ss.

${ }^{46}$ Domínguez Hidalgo, Carmen, El Daño Moral, Editorial Jurídica de Chile, Santiago, 2000, T. II, pp. 598-609.

${ }^{47}$ Corral Talciani, Hernán, Lecciones de responsabilidad civil extracontractual, Editorial Jurídica de Chile, Santiago, 2003, pp. 33-34.

${ }^{48}$ Esta es la posición general, la que admite dos excepciones: cuando exista pacto expreso o cuando el ilícito civil sea a la vez un ilícito penal. Alessandri Rodríguez, Arturo, De la responsabilidad extracontractual en el Derecho civil chileno, Editorial Jurídica de Chile, Santiago, 2005, pp. 63-64.
} 
normas; si se trata de un concurso impropio (de acciones), tenemos dos acciones que no son excluyentes entre sí; y un tercer caso sería el de conflicto normativo (de normas), en donde hay una sola pretensión, que exige la exclusión de una norma mediante la aplicación del principio de especialidad ${ }^{49}$.

En síntesis, por un lado, se considera que la responsabilidad civil contractual y extracontractual constituyen un concurso de normas, por lo que existiría una única acción; por otro, se trataría de un concurso de acciones en donde hay dos pretensiones diferentes, basadas en normas legales distintas que obligan a la parte a realizar de manera precisa la configuración de la acción impetrada; o en otra variante de esta misma teoría, el demandante tiene la posibilidad de optar por el régimen que estime más beneficioso para sus intereses, pero invocado uno, ya no es posible iniciar un nuevo proceso en base al otro régimen ${ }^{50}$.

También en la doctrina civil actual se ha planteado la posibilidad de concurrencia de acciones o normas generales y especiales contenidas en el $\mathrm{CC}^{51}$ o en leyes especiales, como la LPDC ${ }^{52}$; LBGMA $^{53}$, sin embargo, no hay una referencia expresa a la existencia de un concurso de acciones o normativo, pero en general, se otorga la opción al particular al momento de entablar la acción que considere más beneficiosa para la obtención del petitum de la acción, sin

\footnotetext{
${ }^{49}$ Barros, Tratado, cit. nota n. 2, pp. 1056-1057. Este autor manifiesta que el concurso de responsabilidades es un concurso de normas, porque "la pretensión indemnizatoria tiene por fundamento dos conjuntos de normas diferentes, de modo que, técnicamente, se trata de un concurso de normas que son fundamento de la responsabilidad".
}

${ }^{50}$ Alonso, El problema, cit. nota n. 45, p. 388.

${ }^{51}$ De la Maza Gazmurı, Íñigo, "El régimen de los cumplimientos defectuosos en la compraventa", Revista Chilena de Derecho, vol. 39, № 3, 2012, pp. 629-663. En este trabajo y en otros de la doctrina civil chilena se utiliza la expresión remedios, tomada del sistema anglosajón (remedies) a efectos de esquivar la discusión de si se trata de una norma o una acción. Confróntese VIDAL Olivares, Álvaro, "EI incumplimiento y los remedios del acreedor en la propuesta de modernización del derecho de las obligaciones y contratos español", Revista Chilena de Derecho Privado, № 16, 2011, pp. 243-302.

${ }^{52}$ Confróntese CAPRILE, Bruno, "Las acciones del comprador insatisfecho: el cúmulo actual (ley de protección al consumidor, vicios redhibitorios. Error sustancial, resolución por incumplimiento) y la tendencia al deber de conformidad en el Derecho Comparado", en MANTILLA, Fabricio y otro (coord.), Estudios de Derecho privado en homenaje a Christian Larroumet, Fundación Fueyo Universidad Diego Portales, Universidad del Rosario, Santiago, 2008, pp. 561-602; Barrientos Camus, Francisca, "El vicio de la cosa comprada. La noción de vicio redhibitorio en el régimen de saneamiento del Código Civil y la Ley sobre protección de los derechos de los consumidores", en DE LA MAZA, ínigo (coord.), Incumplimiento contractual. Nuevas perspectivas, Cuadernos de Análisis Jurídico, Colección Derecho privado VII, Ediciones Universidad Diego Portales, Facultad de Derecho, 2011, pp. 363-385.

${ }^{53}$ VIDAL Olivares, Álvaro, "Las acciones emanadas del daño ambiental y el régimen de responsabilidad aplicable", en PizarRo WILson, Carlos (dir.), Regímenes especiales de responsabilidad civil, Cuadernos de Análisis Jurídico, Colección de Derecho Privado IV, Ediciones Universidad Diego Portales, 2008, pp. 191-210; PiZARro Wilson, Carlos, "La responsabilidad por daño ambiental en perspectiva civil", en MANTILLA, Fabricio y otro (coord.) Estudios de Derecho privado en homenaje a Christian Larroumet, Fundación Fueyo Universidad Diego Portales, Universidad del Rosario, Santiago, 2008, pp. 387-400. 
que quede claro por el tenor sustantivo de los trabajos, cuáles son las vías procedimentales o los efectos en procesos conexos de esta opción.

\section{b) En los sistemas de Derecho continental-europeo}

El fenómeno de la concurrencia ha sido analizado desde los albores de la disciplina procesal en Alemania, Italia y en España.

Debemos a la doctrina alemana el nacimiento de la disciplina jurídicoprocesal como autónoma del Derecho material, y el concepto de pretensión como máxime de la distinción entre lo procesal y lo sustantivo. Este término acuñado por Windscheid, quien señala al respecto que la expresión actio en el lenguaje actual, es sinónimo de pretensión en algún sentido, pero que no es menos cierto que el primer concepto "(...) sirve para designar, no la pretensión, sino el hecho de hacer valer esa pretensión ante los tribunales" ${ }^{\prime 54}$.

Se ha entendido por pretensión la afirmación de un derecho material en el proceso, o la afirmación de un estado de cosas y una petición invocada por el actor en el proceso ${ }^{55}$.

En cuanto al concurso indica este autor que puede ocurrir que para obtener de un tercero un mismo objeto se disponga de varias acciones, sin embargo, eso no será razón para reclamarlo más de una vez, manifestando que la consecuencia derivada de la obtención de un objeto mediante una de las acciones concurrentes es la exclusión de todas las demás acciones que tenían el mismo objeto. Hay propiamente concurso de acciones, cuando existiendo dos o más, la satisfacción de una excluye y destruye a la otra o cuando se utiliza una de ellas, pudiendo existir efecto excluyente por satisfacción procesal o utilización de una de las acciones ${ }^{56}$.

En Italia, ChiOvenda explica que existe concurso de acciones en tres casos: ante la identidad del elemento subjetivo de la acción y su petición, pero diferenciándose en la causa de pedir; identidad del elemento subjetivo de la acción y en su causa, pero diferente petición; y, por último, por identidad subjetiva con diferentes prestaciones, pero con un solo fin económico. Señala que la especialidad de estas acciones radica en que pueden ser satisfechas sólo una vez, sin que esto suprima su diversidad ${ }^{57}$.

En cambio, hay concurso de normas "(...) únicamente tiénense cuando el mismo hecho puede estar sometido a diversas normas y se trata de averiguar

\footnotetext{
${ }^{54}$ WindSCHEID, "La 'actio'", cit. nota n. 16, p. 12.

55 Schwab, Karl Heinz, El objeto litigioso en el proceso civil, EJEA, Buenos Aires, 1968, pp. 6-7.

${ }^{56}$ WindSCHEID, "La 'actio'", cit. nota n. 16, pp. 49-52; 57.

${ }^{57}$ Chiovenda, Giuseppe, Principios de Derecho procesal civil, REUS, Madrid, t. I, 1977, p. 360.
} 
cuál es la norma aplicable, lo cual ha de decidir siempre el juez, incluso de oficio" $^{\prime \prime 2}$.

Por su parte, LieBman manifestando que de un grupo de derechos concurrentes emanan otras tantas acciones concurrentes, define la concurrencia en ambos casos cuando derechos o acciones están vinculados funcionalmente lo que supone que la satisfacción de uno de ellos extingue también el otro, aunque cada uno de los derechos o las acciones sean separables y tutelables de manera individual ${ }^{59}$.

Propone una solución de los concursos secundum eventus litis, ya que indica que si se obtiene una sentencia favorable a la petición formulada, se extinguen las acciones concurrentes porque desaparece el interés para accionar en los eventuales procesos posteriores; en cambio, si se rechaza la demanda, indica que es posible la interposición de las demás acciones ${ }^{60}$.

En España, Gómez ha señalado que resulta determinante en la distinción de un concurso de normas de uno de acciones si a los supuestos abstractos de las normas (dos o más) que eventualmente resulten aplicables, pertenece o no la relación jurídica implicada. Por ejemplo, si para la entrega de una cosa se puede hacer valer un derecho real como el dominio y, a la vez, un derecho personal emanado de un contrato; si la propiedad o la convención -las relaciones jurídicas involucradas- forman parte o no del supuesto de hecho de la norma ${ }^{61}$.

El supuesto de hecho de la norma si se compone también por la relación jurídica implicada aparte de los hechos concretos, no puede estar formado objetivamente por ambas relaciones jurídicas, sino que por una sola -la causa de pedir-y ello determinaría que si existen dos o más relaciones jurídicas, existen dos o más acciones diferenciadas por sus elementos objetivos ${ }^{62}$.

Estos problemas derivados de los fundamentos de hecho y jurídicos de la causa de pedir que eventualmente no sean alegados por la actora y que supongan la posible interposición de nuevos juicios, es un tema superado en España debido a la incorporación del artículo 400 de la LEC 2000, que establece como carga a la parte demandante aducir en la demanda cuantos hechos o títulos jurídicos resulten conocidos o puedan invocarse al tiempo de interponerla, sin que sea admisible reservar su alegación para un proceso posterior. De este modo, la ley exige que la parte acumule en un solo proceso todas las acciones que tenga, bajo sanción de no ser oído después.

\footnotetext{
${ }^{58}$ Chiovenda, Principios, cit. nota n. 57, p. 361.

${ }^{59}$ LieBman, Enrico Tullio, Manual de Derecho Procesal Civil, EJEA, Buenos Aires, 1980, p. 147.

${ }^{60}$ LieBMAn, Manual, cit. nota n. 59, p. 148.

${ }^{61}$ Gómez Orbaneja, Emilio, "Concurso de leyes y concurso de acciones en el Derecho civil", en Derecho y Proceso, Civitas Thompson-Reuters, Pamplona, 2009, p. 154.

${ }^{62}$ Gómez, "Concurso", cit. nota n. 61, pp. 154-155.
} 
Del análisis de los planteamientos de la doctrina procesal, consideramos que no es lo mismo un concurso de normas que un concurso de acciones. No siempre de dos normas emanan dos derechos subjetivos distintos y tampoco necesariamente de una norma emana una acción, ya que hay casos en donde la consecuencia jurídica de un hecho está afirmada en dos normas y la referencia que efectúe el legislador en dos normas de una misma petición fundada en unos mismos hechos con significación jurídica no puede determinar necesariamente la existencia de dos acciones diversas. El problema, a nuestro juicio, de la tipificación del concurso como de normas o de acciones y de los efectos procesales que dicha calificación determina, deriva de la existencia una delgada línea para diferenciar las áreas del Derecho sustantivo y del Derecho procesal ${ }^{63}$.

\section{Elementos definidores:}

relación o título jurídico, causa de pedir y petición

Siguiendo con nuestro análisis, y considerando que en el concurso de normas hay un efecto material doblemente establecido en la ley y en el concurso de acciones existen dos o más mecanismos de protección delimitados y configurados de manera autónoma para una misma petición, la pregunta que debe ser respondida es cuándo estamos ante mecanismos de protección o acciones delineados de forma diferente.

En este sentido, debemos analizar cuáles son los componentes que configuran o identifican las acciones objetivamente, esto es, la petición y la causa de pedir, en definitiva, lo que constituye el objeto del proceso.

Objetivamente, el proceso está formado por la causa de pedir y las peticiones formuladas por el actor en el momento de deducir su acción, esto es, en la demanda y en las eventuales transformaciones de ésta, dependiendo de si ello es aceptado o no dentro del ordenamiento jurídico en cuestión.

La idea básica del acto de la demanda es la afirmación de un derecho que efectúa el actor de corresponderle un determinado efecto de contenido-jurídico. Esta declaración que realiza el actor al inicio del proceso constituye el núcleo de la actividad procesal, manifestación que está determinada por dos factores: uno objetivo, que está dado por el bien jurídico cuya protección o concesión se solicita al juzgador; y otro causal, que está constituido por el conjunto de hechos y acaecimientos de la vida real que originan la petición del demandante, sin que los fundamentos jurídicos argüidos por el actor formen parte de la causa de pedir de la acción ${ }^{64}$.

\footnotetext{
${ }^{63}$ Hercé Quemada, Vicente, "Derecho procesal civil y Derecho civil: su delimitación", Boletín mexicano de Derecho comparado, № 24, 1975, pp. 577-594.

${ }^{64}$ Berzosa, Demanda, cit. nota n. 7, pp. 27-28.
} 
La libertad del juez al momento de la calificación jurídica está limitada por aquellos hechos que individualizan la petición del demandante, que constituyen su causa de pedir; ello implica que ningún razonamiento jurídico integra esta causa y, por consiguiente, no limita la libre elección de los motivos jurídicos, razonamientos o normas que el juzgador estima adecuadas en su resolución. La calificación jurídica no es competencia del actor sino del juez, y si el actor la realiza, no es determinante para quien juzga ${ }^{65}$, aunque ordenamientos jurídicos como el nuestro -art. 254 del CPC- lo exijan como requisito de interposición de la demanda.

Sin embargo, este argumento no puede interpretarse de manera tal que los hechos que configuran la causa de pedir sean planteados "(...) en un sentido tan aséptico que llegue a desvincularse de la significación jurídica que estos hechos han de tener, para constituir, en unión de la petición, el objeto del proceso" ${ }^{\prime \prime 6}$, ya que de modo contrario serían incomprensibles bajo la luz del Derecho. En este sentido, Guasp distingue lo que sería la individualización de la pretensión, de la fundamentación de la misma, formando parte del objeto del proceso sólo la primera. Una fundamentación adecuada permite que el juez acoja la demanda, pero no configura el objeto del proceso ${ }^{67}$.

En contra de estos razonamientos, Tapia manifiesta expresamente que la causa de pedir tiene dos elementos: uno fáctico y otro jurídico; pero, a su vez, el elemento jurídico se divide en dos subelementos: la referencia normativa y la calificación jurídica. Sólo este último formaría la causa de pedir ${ }^{68}$.

Nos parece que todos estos autores discrepan en la forma y en la terminología utilizada, pero en realidad apuntan a cuestiones iguales. Sin duda que la referencia legal no es parte de la causa de pedir, pero eso que Berzosa llama significación jurídica de los hechos es lo que Tapia Ilama calificación jurídica. En conclusión, siempre que un justiciable acude ante un órgano jurisdiccional, lo que solicita es tutela jurídica, por lo que la configuración no puede abstraerse de un componente de Derecho.

En cuanto al elemento fáctico, los hechos que son esenciales para configurar el objeto del proceso y que constituyen la causa petendi son los que delimitan la petición, que la distinguen de las demás, que hacen que ese objeto litigioso sea ese y no otro, diferenciable de otros que pueden guardar

\footnotetext{
${ }^{65}$ Berzosa, Demanda, cit. nota n. 7, p. 48.

${ }^{66}$ Berzosa, Demanda, cit. nota n. 7, p. 49.

${ }^{67}$ GuAsP, Jaime, "La pretensión procesal", Anuario de Derecho Civil, Madrid, Instituto Nacional de Estudios Jurídicos, Madrid, 1952, pp. 50-51.

${ }^{68}$ Tapia Fernández, Isabel, El objeto del proceso. Alegaciones. Sentencia. Cosa Juzgada, La Ley, Madrid, 2000, p. 25.
} 
conexión o semejanzas, y que incluso implican una misma solicitud referida a hechos diversos ${ }^{69}$.

De este modo, se pretende dar respuesta a la histórica disputa procesal sobre si el elemento jurídico forma parte o no de la causa de pedir de las acciones ${ }^{70}$. Así las cosas, para la teoría que incluye el elemento jurídico -substanciaciónuna nueva alegación de carácter jurídico generaría una mutación en el objeto del proceso o una nueva acción, y para la otra -individualización-, no.

Fairén también plantea que la aplicación irrestricta de una u otra teoría no da una respuesta adecuada a este tipo de problemas. "No sólo los hechos ni el derecho fundamentan una demanda, sino que para promover una pretensión es necesario relacionar los hechos con su figura legal"71.

En Chile, Pereira sigue la teoría de la individualización, al señalar que las acciones serán diversas si el título jurídico argüido en uno y otro juicio son distintos, graficando su postura con un ejemplo, en la interposición de una acción reivindicatoria fundando el derecho de dominio en una donación y una posterior, en una compraventa o legado ${ }^{72}$.

A nuestro juicio, el elemento determinante radica en si la relación jurídica implicada forma parte o no de la causa de pedir de la acción. Si ello es así, no será lo mismo invocar la propiedad en un caso o el contrato en otro, estando así ante dos acciones distintas. Si ello no es efectivo, si sólo los hechos son los que identifican la acción, estaremos ante una misma acción sin ser relevante si se arguye el dominio o el derecho personal emanado del contrato.

Si la norma en cuestión considera dentro del supuesto de hecho una relación jurídica distinta como su fundamento, el mecanismo de tutela de ese derecho -la acción- es distinta a la que tutela otra diversa relación jurídica. Al contrario, si la relación jurídica que sustenta la acción es la misma en las dos normas, estaremos en un concurso de normas, porque tanto hechos externos y relación jurídica en ambas son idénticos.

\footnotetext{
${ }^{69}$ Berzosa, Demanda, cit. nota n. 7, p. 32.

${ }^{70}$ Para ver una síntesis completa de las teorías de la individualización y de la substanciación en España, confróntese De La Oliva SANTOS, Andrés, Objeto del proceso y cosa juzgada en el proceso civil, Thompson Civitas, Madrid, 2005, pp. 52 y ss.; en Alemania, confróntese FaIRÉN GuiltéN, Víctor, La transformación de la demanda en el proceso civil, Porto, Santiago de Compostela, 1949, pp. 21 y ss.

${ }^{71}$ FAIRÉN, La transformación, cit. nota n. 70, p. 76.

72 Pereira Anabalón, Hugo, La cosa juzgada formal en el procedimiento civil chileno, Editorial Jurídica de Chile, Santiago, 1954, p. 58. Posición contraria a la de BerzosA, que manifiesta que si la causa de pedir se sustenta en un derecho absoluto -como el dominio- el título o relación jurídica esgrimida no es en este caso el antecedente o causa del dominio, sino el dominio mismo. "Esta singularización de la causa de pedir cuando se litiga sobre un derecho absoluto, lleva consigo una importante consecuencia: alegado el derecho de que se trate puede ser concedido por cualquier causa, y denegado por una se excluyen las demás posibles". Berzosa, Demanda, cit. nota n. 7, p. 35.
} 
Resulta clave, a nuestro entender, considerar dos vínculos para la realización del juicio comparativo ${ }^{73}$ necesario para determinar la existencia del concurso de acciones: el primero, relativo a la relación que debe existir entre los elementos fundantes de hecho y la significación jurídica de éstos en las acciones en análisis; y la segunda, relativa a la relación entre estos dos elementos y la petición formulada.

Desde una perspectiva práctica, el concurso de acciones confiere varios mecanismos para obtener una misma finalidad, de modo que pueden utilizarse diversas vías para satisfacerla. Pero hasta que ese fin no es satisfecho mediante la estimación firme de la pretensión, ninguna de las normas excluye a la otra. A diferencia de lo que sucede en los supuestos de concurso de normas, el cual se caracteriza porque una de las normas excluye la aplicación simultánea de la otra ${ }^{74}$.

Pero para saber si existe concurso o no, es esencial identificar los elementos de las acciones eventualmente aplicables y realizar un juicio comparativo entre ambas para aceptar la concurrencia o rechazar la interposición de la misma acción en un segundo proceso.

\section{Algunas soluciones al problema de LA CONCURRENCIA}

Como hemos esbozado en los párrafos anteriores, la problemática de la concurrencia dentro del proceso civil tiene dos vías de solución: una legislativa y otra dogmática.

\section{Normas legales que expresamente regulan la situación de concurrencia}

En este sentido, nuestro legislador ha regulado expresamente qué ocurre respecto de las acciones que emanan sobre un mismo hecho o las normas que pueden ser aplicadas a una misma situación fáctica, pudiendo establecer expresamente la compatibilidad de las acciones o las normas, o su incompatibilidad.

Estimamos que son hipótesis en nuestro Derecho de concurrencia compatible la acción de protección y varias de las acciones indicadas como competencia de los tribunales ambientales, conforme el artículo 17 de la Ley $\mathrm{N}^{\circ}$ 20.600, puesto que es el propio constituyente quien ha señalado expresamente que la acción de protección se deduce sin perjuicio de otras acciones y derechos que puedan hacerse valer.

\footnotetext{
${ }^{73}$ De la Oliva Santos, Andrés, De la cosa juzgada (civil, contencioso-administrativa y penal, con examen de jurisprudencia del Tribunal Constitucional), Editorial Centro de Estudios Ramón Areces S.A., Madrid, 1991, p. 91.

74 Bellido Penadés, Rafael, La tutela frente a la competencia desleal en el proceso civil, Comares, Granada, 1998, p. 150.
} 
Sin embargo, la ICA de Santiago, en un fallo reciente, ha señalado la incompatibilidad de los dos mecanismos de tutela, declarando inadmisible una acción de protección deducida por un grupo de pobladores de la comuna de Lo Espejo en contra de Servicio de Evaluación Ambiental señalando "que los hechos descritos a fojas 38, sobrepasan los márgenes del recurso interpuesto, toda vez que las materias planteadas deben ser ventiladas en el procedimiento contenido en la Ley $\mathrm{N}^{\circ}$ 20.600, ante el Tribunal Ambiental creado especialmente al efecto, lo que se contrapone con la naturaleza cautelar de la acción de protección"75.

También son casos de concurrencia compatible las acciones que se pueden entablar por unos mismos hechos en base a la LCD, la LPDC, LPInd, LPInt y el DLLC. En este caso, podrá tratarse de un concurso de normas o de acciones, dependiendo del objeto que se persiga con la acción deducida en juicio. Sin embargo, la propia LCD establece en su artículo $2^{\circ}$ que los hechos constitutivos de competencia desleal también podrán motivar la interposición de otras acciones contempladas en los cuerpos legales señalados.

En cambio, un caso de concurrencia de normas incompatibles y, en definitiva, un falso concurso, lo constituye la acción de tutela laboral y la acción de protección, ya que el Código del Trabajo señala en el inciso final del artículo 485 expresamente que una vez interpuesta la acción de protección no se podrá interponer la acción de tutela laboral.

También es un caso de incompatibilidad la acción de amparo del artículo $3^{\circ}$ de la Ley $N^{\circ} 20.609$ que establece medidas en contra de la discriminación, ya que el artículo $6^{\circ}$ establece expresamente la pertinencia de la declaración de inadmisibilidad de esta última cuando haya sido presentada previamente una acción de protección, de amparo o de tutela laboral por los mismos hechos.

Del mismo modo, son incompatibles la acción de protección y el amparo tributario del artículo $129 \mathrm{~K}$ del Código Tributario (reformado por la Ley № 20.322), puesto que la misma disposición señala la imposibilidad de impetrarlo si ya se interpuso acción constitucional.

En estos casos, aunque el legislador haya sido efectivamente más preciso otorgando una solución expresa a la concurrencia, detectamos un problema que en nuestro Derecho procesal civil se produce ante la incompatibilidad de acciones para la obtención de un mismo beneficio jurídico: la diversa vía procedimental en la tramitación de las acciones concurrentes.

Como hemos dicho supra, el Derecho procesal civil ha experimentado también el fenómeno de descodificación, por lo que la substanciación de los procesos mediante las reglas del procedimiento de aplicación general contenidas

\footnotetext{
${ }^{75}$ Binimelis y otros con Servicio de Evaluación Ambiental, Corte de Apelaciones de Santiago, acción de protección, 28 de mayo de 2013, Rol № 26.994-2013. En: http://corte.Poderjudicial.cl/SITCO RTEPORWEB/ [visitado el 05/07/2013].
} 
en el libro II del CPC, no goza efectivamente de este carácter conforme el deseo original del codificador de 1902, creándose con posterioridad a su dictación diversas vías de tutela de cognición sumaria, que se caracterizan por restringir la fase probatoria del procedimiento, limitando en muchos casos la posibilidad que tienen las partes para incidir en el contenido de la sentencia definitiva del proceso; y por una faz externa especial diversa de la cognición ordinaria, por no obedecer a la estructura de éste ${ }^{76}$.

Lo anterior, no resulta grave per se si se mantienen las fases que debe tener todo proceso de cognición, sea este sumario o no, garantizando el ejercicio de los contenidos mínimos del debido proceso y del derecho a la tutela judicial efectiva: la posibilidad de acceder a un órgano jurisdiccional del cual se obtenga una sentencia de fondo motivada, pudiendo incidir las partes en dicho pronunciamiento a través de la realización de alegaciones de hecho y de Derecho y de la posibilidad de acreditar dichas alegaciones a través de la prueba pertinente ${ }^{77}$.

Grafiquemos lo anterior con un ejemplo a propósito de la acción de protección como vía de tutelar un derecho fundamental. Supongamos que iniciamos esta acción que tiene una escasa regulación en la Constitución Política y entregada esencialmente al autoacordado que determina su tramitación, en donde la posibilidad de allegar prueba al juicio está limitada en la práctica esencialmente a la documental. ¿Es realmente la vía idónea para discutir adecuadamente todas las aristas de un derecho? Estimamos que no, y precisamente por ello el constituyente ha normado que la misma se puede interponer sin perjuicio de la posibilidad de incoar otros mecanismos de tutela.

\section{Casos que en no existe norma legal que resuelva la situación de concurrencia}

En la mayoría de los casos que hemos encontrado dispersos en normas de nuestro ordenamiento, el legislador no ha señalado expresamente cómo resol-

\footnotetext{
${ }^{76}$ Baptista Da Silva, Ovidio, Teoría de la acción cautelar, Antonio Fabris Editor, Porto Alegre, 1993, p. 36.

77 El debido proceso "(...) garantiza que la actividad que se desarrollará ante el tribunal de justicia desde que el individuo incoa su actuación o se hace parte en un proceso como demandado o tercero y obtiene una respuesta por parte de éste, sea llevada a cabo de una manera tal que permita desde luego exponer todos los aspectos referidos a cuestiones fácticas y jurídicas que desee invocar, a objeto de incidir sobre la decisión del tribunal de justicia. Se pretende así, con el debido proceso, legitimar de un mejor modo la justicia de la decisión judicial. Ya no es simplemente el derecho a obtener una decisión judicial, que se garantiza con la tutela judicial, sino que es el derecho a incidir en el contenido de esa decisión judicial. En virtud del debido proceso el individuo podrá defenderse deduciendo excepciones, alegaciones y defensas; podrá disponer de un letrado; podrá exigir que el juez que lo juzgará sea un juez natural, independiente e imparcial; podrá presentar medios de prueba; etcétera". Bordalí Salamanca, Andrés, "Análisis crítico de la jurisprudencia del Tribunal Constitucional sobre el derecho a la tutela judicial", Revista Chilena de Derecho, vol. 38, № 2, 2011, pp. 321-322.
} 
ver la interrogante a la compatibilidad o incompatibilidad de las acciones o normas concurrentes.

Por ello, estimamos que en base a la aplicación correcta de las disposiciones procesales vigentes y de la configuración clara de la causa de pedir de las acciones, podemos dar una respuesta coherente a este problema.

\section{a) Concurso de normas}

Recordemos que en los casos de concursos de normas un efecto o consecuencia jurídicos están doblemente normados en la ley.

Estimamos que dentro de un proceso, cuando la situación fáctica que constituye la causa de pedir de la acción está doblemente regulada, en otras palabras, la calificación jurídica es doble, solamente existe un único objeto procesal ${ }^{78}$.

De modo tal, considerando que se trata de un solo objeto procesal, cualquier demanda que se inicie con posterioridad al inicio del primer proceso basada en los mismos hechos, pero con calificación jurídica diferente podrá ser enervada mediante la excepción de litispendencia o de cosa juzgada, dependiendo del estado del primer proceso iniciado.

Del mismo modo, cualquier modificación sobre la calificación jurídica de los hechos de la demanda no constituirá una variación en el objeto del proceso. Es en este concurso en donde el juez tiene potestad para variar la calificación de Derecho que las partes efectúen respecto de los hechos alegados, el virtud de la máxima iura novit curia, debiendo decidir qué norma sustantiva es aplicable al caso.

Esto último, aunque técnicamente es efectivo, genera un problema en relación con las posibilidades de defensa que tienen las partes dentro del proceso ${ }^{79}$, ya que si el juicio ha discurrido sobre determinado debate fáctico y jurídico, y posteriormente el juez puede fallar en base a argumentación jurídica no discutida, sólo queda a las partes deducir recursos en contra de la sentencia dictada, siempre que el ordenamiento los contemple, situación cada vez más compleja a la luz de las nuevas tendencias legislativas a nivel procesal de limitar el doble grado de conocimiento ${ }^{80}$, sin embargo, ya se encuentra agotada la instancia sin que las partes hayan sido oídas respecto de si existen motivos por los cuales estimaron la impertinencia de esas calificaciones omitidas ${ }^{81}$.

\footnotetext{
${ }^{78}$ Berzosa, Demanda, cit. nota n. 7, pp. 56-57.

${ }^{79}$ Sobre cómo han abordado este problema varios países europeos, confróntese Ormazábal SánChez, lura novit curia, cit. nota n. 35, pp. 25-45.

${ }^{80}$ Sobre las implicancias de la limitación de la apelación, confróntese PALOMO VéLEZ, Diego, "Apelación, doble instancia y proceso civil oral", Estudios constitucionales, año VIII, № 2, 2010, pp. 465-524.

81 "No puede pretenderse que el juez asuma una posición jurídica innovadora frente a los hechos, sin que haya dado a las partes la posibilidad de discutir esa nueva calificación". Hunter AMPUero, Iván,
} 
Ejemplos de este tipo de concurrencia son la eventual demanda interpuesta alegando el hecho de la compra de un bien, ya sea por las normas del CC de la compraventa o las de contrato de consumo de la $\mathrm{LPDC}^{82}$; la acción de protección en relación con el amparo económico y con acciones de cesación del DLLC.

En estos casos, claramente los hechos que motivan la interposición de las demandas constituyen una única relación amparada por el Derecho en dos o más normas.

\section{b) Concurso de acciones}

En cambio, en el concurso de acciones la petición formulada por el justiciable puede ser configurada, delimitada o individualizada de manera distinta dependiendo de la norma jurídica que se invoca, la que de todas formas no será parte de la causa de pedir de la acción deducida ${ }^{83}$. Lo mismo parece establecer una sentencia de la Corte Suprema cuando señala "cumple con la ley la sentencia que contiene los fundamentos de las resoluciones aunque ellos pudieran no guardar congruencia con la cuestión debatida" ${ }^{44}$.

En estos casos, como existen acciones diversas y cada una de ellas configura un objeto procesal diverso, BERZOSA concluye coherentemente con su posición que la interposición de una nueva demanda fundada en la acción concurrente, no queda cubierta con la excepción de litispendencia o cosa juzgada derivada del primer proceso $^{85}$.

También, en los casos de concursos de acciones, el juez en el proceso civil está limitado a la configuración que el actor ha dado a su demanda en virtud del principio dispositivo, sin que pueda variar el significado jurídico que el actor ha dado a los hechos invocados en el libelo ${ }^{86}$. En este sentido, TAPIA ha manifestado que el límite a la potestad que tienen los tribunales de

\footnotetext{
"Iura novit curia en la jurisprudencia civil chilena", Revista de Derecho, Universidad Austral de Chile, vol. XXIII, No 2, 2010, p. 200.

${ }^{82}$ Por ejemplo, un fallo del $3^{\circ}$ Juzgado civil de Coquimbo, rechaza la demanda de indemnización de perjuicios promovida por el actor acogiendo la excepción de cosa juzgada debido a que se había sustanciado una acción idéntica basada en la LPDC ante uno de los juzgados de Policía Local de la misma comuna. Maldonado con Inmobiliaria y Constructora El Solar de Peñuelas, Tercer Juzgado de Letras de Coquimbo, Procedimiento ordinario civil sobre resolución de contrato con indemnización de perjuicios, 29 de mayo de 2012 Rol No 1009-2011, c. 7. En: http://civil.poderjudicial.cl/ CIVILPORWEB/?opc_menu=7 [visitado el 31/07/2013].

${ }^{83}$ Berzosa, Demanda, cit. nota n. 7, pp. 56-58.

${ }^{84}$ Benavente con Junta de Beneficencia de Concepción, Corte Suprema, casación en la forma civil, 12 de noviembre de 1904, RDJ, T. III, Parte 20, Sec. $1^{\text {a }}$, 1905-1906, p. 374.

${ }^{85}$ Berzosa, Demanda, cit. nota n. 7, pp. 66 y siguientes.

${ }^{86}$ Prieto-Castro y Ferrándiz, Leonardo, "El cambio del punto de vista jurídico", Revista de Derecho Procesal, publicación iberoamericana y filipina, $\mathrm{N}^{\circ} 1,1956$, p. 7.
} 
justicia de aplicar el derecho al caso viene determinado por la configuración que los litigantes hayan querido establecer respecto de sus derechos subjetivos ${ }^{87}$.

Igual criterio podemos encontrar en un fallo de la Corte de Apelaciones de La Serena que, conociendo de un recurso de nulidad en materia laboral, anuló el fallo señalando que la juez de la instancia había fallado respecto de acciones no deducidas por las partes, incurriendo en la causal de nulidad por ultrapetita. La demanda que daba inicio al proceso laboral de tutela establecía la ocurrencia de conductas vulneratorias a la libertad de trabajo y el derecho de propiedad, y la juez dio por establecidas la existencia de conductas calificadas como prácticas antisindicales y condenó a la demandada por ello. "Sin embargo, en ninguna parte de la demanda se hace mención ni obviamente ésta se fundamenta en la existencia de prácticas antisindicales, ni se invoca el derecho a la libertad sindical, por lo que la sentencia apartándose de los límites del asunto debatido (...) ha extendido su fallo a puntos no sometidos a la decisión del tribunal" ${ }^{\prime \prime}$.

Lo que caracteriza al concurso de acciones es la exclusión de toda otra acción concurrente cuando se interpone una de ellas, y ello independiente del resultado que se produzca en el proceso, acogiendo o rechazando la demanda. En definitiva, el demandante tiene un derecho a optar por la vía que le parezca más favorable. Sin embargo, este planteamiento no atiende a la necesidad de certeza en las relaciones jurídicas, que es una finalidad mediata del Derecho, y lo inoficioso que es mantener pendientes de enjuiciamiento múltiples vías procesales para la obtención de un mismo beneficio jurídico. Es avalar la mala fe procesal y la obtención de ventajas procesales ilegítimas pudiendo corregir los errores procesales iniciando juicios en donde se discutan los mismos hechos que ya fueron objeto de otro. Lo anterior atenta contra la buena fe procesal y se constituye como un abuso del derecho ${ }^{89-90}$.

\footnotetext{
${ }^{87}$ TAPIA, El objeto, cit. nota n. 68, p. 24.

${ }^{88}$ Sindicato Empresa Minera Lolol actual Tambillos con Sociedad Contractual Minera Tambillos, Corte de Apelaciones de La Serena, recurso de nulidad laboral, 25 de noviembre de 2009, Rol T № 113 2009, c. 10. En: www.poderjudicial.cl [visitada el 27/11/2011].

${ }^{99}$ PICó I JunOY, Joan, La buena fe procesal, Depalma, Ibáñez, Pontificia Universidad Javeriana, Bogotá, 2011, pp. 79 y ss.; en Chile sobre este tema a nivel procesal, confróntese Romero SeGUeL, Alejandro, Curso de Derecho procesal civil. La acción y la protección de los derechos, Editorial Jurídica de Chile, Santiago, t. I., 2006, p. 70.

${ }^{90}$ Con el objeto de evitar múltiples juicios en base a los mismos hechos, resulta conveniente desde la perspectiva práctica, la deducción de las acciones incompatibles de manera subsidiaria, tal como lo autoriza el artículo 17 del CPC.
} 
Ejemplos de este tipo de concurso son en nuestro Derecho las acciones por responsabilidad civil contractual y extracontractual derivadas de un mismo hecho, reguladas en nuestro $\mathrm{CC}^{91}$.

También, una situación de hecho que ofrece en nuestro ordenamiento tanto la concurrencia de concursos de normas como de acciones es la eventual persecución de una indemnización de perjuicios por los vicios, defectos o fallas en la construcción de un edificio.

Arguyendo el contrato de compraventa del inmueble, se puede demandar alegando la aplicación de las normas de incumplimiento contractual y las especiales sobre arrendamiento de servicios inmateriales, ambas del CC; o también las de los artículos 18 y 19 de la LGUC. En todos estos casos estamos ante concursos de normas, una sola acción, ya que el título que se alega como sustrato de la acción es la relación contractual.

Sin embargo, nada impide que podamos argüir como sustento la culpa del demandado, ya no la relación contractual, basándonos en el régimen de responsabilidad extracontractual del CC. En este último caso, esta acción es concurrente con la derivada de la responsabilidad contractual.

En materia de salud, para perseguir indemnización de perjuicios por daños ocasionados; se debe distinguir si se trata de servicios públicos o privados. Si éstos son públicos, se pueden aplicar el régimen de responsabilidad extracontractual en virtud del artículo 2314 del CC; el régimen de responsabilidad por falta de servicio del artículo 38 de la Ley $N^{\circ} 19.966$, o el régimen de responsabilidad objetiva, fundado en los artículos $6^{\circ}, 7^{\circ}$ y 38 de la $\mathrm{CPRCH}$ en relación con los artículos $4^{\circ}$ y 42 de la LOCBGAE.

Si los servicios de salud son privados, resultan aplicables los regímenes civil contractual y extracontractual, por aplicación de los artículos 1553 y 2314 del $\mathrm{CC}$, respectivamente.

\section{Consecuencias en el proceso derivadas de la concurrencia}

De este análisis concluimos que las consecuencias procesales de un concurso u otro son distintas.

Tratándose del concurso de normas, la acción que se tiene siempre será una sola, consecuencialmente la relación jurídica también, sólo las normas jurídicas aplicables al caso pueden ser eventualmente más de una, pudiendo alegar la actora una o todas, sin que el juez se encuentre ligado a la calificación jurídica que de la relación material hagan las partes en virtud de la aplicación del aforismo iura novit curia, pudiendo resolver el asunto en base a una norma

${ }^{91}$ Lo anterior también tiene un sustento legal. El artículo 1437 del CC señala expresamente que son fuentes de las obligaciones tanto el contrato como de un hecho que ha provocado injuria o daño a otro. CORRAL, Lecciones, cit. nota n. 47, p. 27. 
no alegada. Dado que la acción es una sola, nuevos procesos iniciados con posterioridad estarán cubiertos por la cosa juzgada o la litispendencia de la sentencia definitiva dictada en el primero.

Ahora, si estamos frente a un concurso de acciones, las que configuran objetos procesales distintos, éstas pueden ser promovidas para la defensa del derecho subjetivo, sin embargo, una vez impetrada una, no es posible interponer las demás ${ }^{92}$ por identidad parcial de objeto. El juez se encuentra inhibido de modificar el objeto procesal, debiendo pronunciarse respecto de éste y no de otro, so pena de incongruencia de la sentencia, vicio que podría ser causal de recurso de casación en la forma, por ultrapetita ${ }^{93}$.

Respecto de procesos posteriores, estimamos que es procedente la solicitud de acumulación de autos conforme el artículo 92 del CPC si ambos procesos están pendientes por ser conexas las acciones, no procediendo acoger las excepciones de litispendencia y cosa juzgada.

A continuación, referiremos más detalladamente algunas de las consecuencias indicadas.

\section{a) Configuración de la demanda, del objeto procesal y mutatio libeli}

La demanda como acto procesal es la oportunidad en que el demandante delinea su acción, estableciendo contra quien la deduce, cuáles son sus fundamentos de hecho y de Derecho y cuáles son las peticiones que somete al tribunal, todo ello en virtud de las exigencias legales del artículo 254 del CPC.

En este sentido, podemos extrapolar a propósito de esta disposición las conclusiones que Prieto-Castro obtenía a propósito del artículo 524, II, de la antigua LEC española de 1881, que en similares términos refería los requisitos de la demanda, estableciendo que lo que exige esta disposición legal es una calificación jurídica del derecho, relación jurídica o hecho que, finalmente, por aplicación de la regla iura novit curia, no vincula al órgano jurisdiccional ${ }^{94}$.

De este modo, la indicación legal concreta no es constitutiva del objeto del proceso. Esta exigencia legal se explica debido a la concepción que del proceso tiene nuestro legislador histórico del CPC, concepción romana de la acción como el derecho subjetivo puesto en juicio ${ }^{95}$.

\footnotetext{
${ }^{92}$ Desde la perspectiva civil, no sería posible acceder a la segunda acción, puesto que habría una doble indemnización por el mismo daño, esto es, un enriquecimiento sin causa. AlESSANDRI, De la responsabilidad, cit. nota n. 48, p. 61.

93 Botto OAkley, Hugo, La incongruencia procesal, Córdoba, Lerner, 2006, p. 128.

${ }^{94}$ Prieto-Castro y Ferrándiz, Leonardo, Tratado de Derecho Procesal Civil. Proceso declarativo. Proceso de ejecución, Editorial Aranzadi, Pamplona, t. I, 1985, p. 423.

${ }^{95}$ WINDSCHEID, "La 'actio'", cit. nota n. 16, p. 1.
} 
Como hemos visto, la demanda debe estar configurada por una petición causada por unos hechos y por la forma en que el demandante relaciona éstos con normas del ordenamiento jurídico con el objeto de tutelar un derecho o un interés que arguye como suyo.

Falencias en esta obligación de proponer la demanda configurarán un defectuoso objeto procesal, que motivará un eventual rechazo del libelo. Sin embargo, el demandado en el proceso podrá estar interesado en que el objeto se configure adecuadamente, pudiendo invocar la excepción de ineptitud del libelo como dilatoria de conformidad al artículo 303 número 6 del CPC ${ }^{96}$.

Un primer problema sobre la configuración de la acción deducida surge a propósito de la prohibición de modificación de la demanda o mutatio libeli consagrada en el artículo 312 de nuestro CPC. Dicha disposición señala que el actor podrá modificar y complementar su acción en el escrito de réplica, sin que sea admisible la modificación de aquellas que sean objeto principal del pleito.

¿A qué se refiere nuestro legislador con "acciones que sean objeto principal del pleito"? Lo principal se opone a lo accesorio o secundario, por tanto, podemos pensar que sólo es posible modificar la o las acción(es) deducida(s) de forma secundaria o subsidiarias, pero nuestro Derecho no tiene una regulación sistemática que considere la acumulación sobrevenida y condicional de acciones $^{97}$.

A propósito de las posibilidades de ampliar el objeto del proceso, se presenta la posibilidad al demandado dentro de la fase de discusión de interponer la demanda reconvencional en contra del demandante principal, situación contemplada en el artículo 314 del CPC. En Chile, en principio, la única limitación que impone el legislador para la interposición de la demanda reconvencional es que el tribunal en donde se encuentra radicado el asunto sea competente para conocer de la reconvención estimada como demanda.

Sin embargo, esta amplitud debe ser matizada, ya que la reconvención no es sino una figura de acumulación sobrevenida o sucesiva de acciones al proceso iniciado por el actor ${ }^{98}$, y en ese supuesto, la acción deducida como reconven-

\footnotetext{
${ }^{96}$ Llamada también en la doctrina como defecto legal en el modo de proponer la demanda. Confróntese Prieto-Castro, Tratado, cit. nota n. 94, p. 425.

${ }^{97}$ Sin perjuicio de lo que puede extraerse de lo dispuesto en el artículo 17 del CPC que señala que cuando las acciones sean incompatibles, podrán deducirse de forma subsidiaria. Sobre el concepto de acumulación y sus tipos en nuestro Derecho, confróntese Romero SeGuel, Alejandro, La acumulación inicial de acciones (Artículos 17 y 18 del Código de Procedimiento Civil), Editorial Jurídica ConoSur Ltda., Santiago, 2000, 159 pp.

${ }^{98}$ De la Oliva Santos, Andrés; Díez-Picazo Giménez, Ignacio, Derecho procesal civil. El proceso de declaración, Editorial universitaria Ramón Areces, Madrid, 2004, p. 189.
} 
ción debe tener algún supuesto de conexión objetiva con la acción principal99. Lo anterior se puede afirmar en base a los requisitos generales de acumulación establecidos en nuestro CPC, como veremos en el apartado siguiente.

\section{b) Acumulación de acciones y de procesos}

La acumulación de autos puede ser definida como la reunión de procesos para ser terminados por una misma sentencia ${ }^{100}$, la que se justifica por el grado de conexión objetiva o subjetiva que las acciones a acumular tienen.

Nuestro Derecho procesal civil considera la acumulación inicial de acciones en los artículos 17 y 18 del CPC y la acumulación sobrevenida a través del incidente especial de acumulación de autos en el artículo 92 y siguientes del CPC.

La acumulación inicial parte de la premisa que existen dos acciones compatibles o incompatibles que se interponen de forma conjunta o subsidiaria al presentar la demanda. Esta forma de entablar la demanda sería una manera de paliar el efecto derivado de la multiplicidad de objetos procesales en los concursos de acciones y la posible interposición de nuevos juicios basados en la acción concurrente no interpuesta durante el primer juicio.

En el caso de acumulación sobrevenida, nuestro CPC establece como requisito de procedencia general que se tramiten separadamente dos o más procesos que deban constituir un solo juicio, los que deberían terminar por una sola sentencia con el objeto de mantener la continencia, o unidad de la causa. Luego, ejemplifica situaciones que a juicio del legislador serían hipótesis de acumulación: "1 ${ }^{\circ}$ Cuando la acción o acciones entabladas en un juicio sean iguales a las que se hayan deducido en otro, o cuando unas y otras emanen directa e inmediatamente de unos mismos hechos; $2^{\circ}$ Cuando las personas y el objeto o materia de los juicios sean idénticos, aunque las acciones sean distintas; y $3^{\circ}$ En general, siempre que la sentencia que haya de pronunciarse en un juicio deba producir la excepción de cosa juzgada en otro".

El primer caso descrito, en realidad no considera un caso de conexión, sino más bien de identidad de acciones, siendo procedente la excepción de cosa juzgada o litispendencia; en el segundo caso descrito en el número 1, se plantea un caso de concurso de acciones ya que estamos en presencia de unos mismos hechos de los cuáles emanan dos acciones. En el segundo numeral, se subsumen

\footnotetext{
${ }^{99} \mathrm{Sin}$ embargo, ha existido en legislaciones comparadas la posibilidad de plantear reconvenciones inconexas, situación que se funda esencialmente en la economía procesal, evitando así el nacimiento de nuevos juicios entre las mismas partes, aunque éstos puedan tener objetos diversos. TAPIA FERNÁNDEZ, Isabel, La reconvención. Límites. Jurisprudencia, Editorial General de Derecho S.L., Valencia, 1994, pp. 50-51.
}

${ }^{100}$ Armenta Deu, Teresa, La acumulación de autos, Editorial Montecorvo S.A., Madrid, 1997, p. 34. 
hipótesis relativas a litisconsorcio activo o pasivo por lo que técnicamente no existen varias acciones. Y, por último, se considera la posibilidad de acumular procesos que tengan grados conexión ${ }^{101}$ por lo que la cosa juzgada que producida por la sentencia dictada en uno tiene eficacia positiva -prejudicial- o negativa -irrevocabilidad- de cosa juzgada en el otro.

\section{c) Litispendencia}

La litispendencia está tratada en nuestro ordenamiento como una excepción dilatoria en el artículo 303 del Código de Procedimiento Civil.

Doctrinariamente, se define etimológicamente como la pendencia del proceso, comprensiva, por tanto, de todos los efectos procesales, tantos los producidos con la presentación de la demanda, cuanto van produciéndose hasta la dictación de la sentencia ${ }^{102}$.

La jurisprudencia de nuestros tribunales superiores ha establecido que se produce este estado cuando "(...) se sigue otro juicio sobre la misma cuestión o pretensión entre las mismas partes, lo cual se justifica plenamente, porque de lo contrario, se afectaría la unidad de la cosa juzgada, al sobrevenir dos o más sentencias que pueden resultar contradictorias, y se quebrantaría contra el fin de certeza que en el proceso se persigue. Además, la multiplicidad de procesos sobre la misma cuestión perjudica al demandado al imponerle una pérdida innecesaria de tiempo, trabajo y dinero al soportar nuevamente la actividad jurisdiccional del Estado, ya que la finalidad que ésta persigue en el caso concreto se satisface plenamente con el primer proceso. La litispendencia significa que en los dos procesos se está persiguiendo la solución de un mismo litigio entre unas mismas partes, lo cual mira al contenido de la demanda, en cuanto en ella se encierra la pretensión del demandante"103.

El término anticipado del segundo proceso se justifica porque la seguridad del Derecho exige evitar resoluciones firmes contradictorias y, al mismo tiempo, la economía procesal impone la eliminación de una actividad procesal doble ${ }^{104}$.

101 Calamandrel, Piero, Instituciones de Derecho procesal civil, El Foro, Buenos Aires, t. I, 1996, pp. 295-296.

102 Serra Domínguez, Manuel, "Litispendencia", Revista de Derecho Procesal Iberoamericana, № 3, 1969, pp. 653-654.

${ }^{103}$ Asesorías e Inversiones Osbon Limitada contra Pérez, Corte de Apelaciones de Talca, recurso de apelación civil, 13 de octubre de 2010, Rol No 465-2010, c. 6. En: www.legalpublishing.cl, Cita Westlaw Chile: CL/JUR/8284/2010 [visitada el 20/01/2012]. En igual sentido, Matamala con Moya, Corte de Apelaciones de Santiago, recurso de apelación civil, 24 de mayo de 2010, Rol № 2714-2009, c. 2. En: www.legalpublishing.cl, Cita Westlaw Chile: CL/JUR/2954/2010 [visitada el 20/01/2012].

104 GutiérRez de Cabiedes, Víctor, "La litis-pendencia", Revista de Derecho procesal iberoamericana, № 3,1969, p. 616. 
Para la determinación en el caso concreto de la procedencia de esta excepción se deben analizar comparativamente las acciones deducidas en ambos procesos. Nuestra jurisprudencia, utilizando el lenguaje del CPC, se refiere a un análisis de la "triple identidad de la cosa juzgada (...) para que exista la triple identidad que deriva del fundamento del recurrente y que se consagra en artículo 177 del Código de Procedimiento Civil; es necesario que existan dos acciones idénticas, que se sustancie entre las mismas partes, que la causa de pedir y la cosa pedida sean las mismas.

De esa forma, basta que alguno de esos elementos sea distinto, para que no exista la triple identidad y, en consecuencia, no exista sea ( $(\mathrm{ic})$ la litis pendencia, o la cosa juzgada en su caso.

Que, de lo expresado anteriormente, se observa que la cosa pedida en ambas acciones no es la misma, por lo que en consecuencia no es posible sostener la triple identidad que plantea el artículo 177 del Código de Procedimiento Civil, y de ahí que no exista litis pendencia"105.

Siguiendo el concepto dado al comienzo, la litispendencia puede ser genérica o específica, en referencia a la existencia de otro proceso con identidad de acción deducida actualmente en curso, o en el segundo caso, respecto de la misma como excepción dilatoria deducible en el segundo proceso iniciado.

Es pacífico en doctrina que el estado de litispendencia se genera con la interposición de la demanda y su admisión a trámite por parte del tribunal competente ${ }^{106}$ y se mantiene dicho estado hasta que no se dicte sentencia firme en el proceso. Una vez ocurrido esto último, la litispendencia abre paso a la cosa juzgada ${ }^{107}$. En nuestra doctrina, ROMERo es de la opinión que este estado se genera a través del emplazamiento, partiendo desde la etimología de la palabra latina ${ }^{108}$.

Desde la perspectiva del concurso de normas, establecida la existencia de un nuevo proceso en donde sólo hay un cambio de la calificación jurídica de los hechos que ya son objeto de un juicio pendiente es procedente el acogimiento de la excepción opuesta. Sin embargo, estimamos que por el carácter dilatorio de la misma, sólo cabe interponerla antes de contestar la demanda, sin que sea posible en otra etapa procesal como las que contempla el artículo

\footnotetext{
105 Equifax Chile S.A. con Millas, Corte de Apelaciones de Santiago, recurso de casación en la forma y apelación civil, 30 de agosto de 2012, Rol No 1697-2012, c. 7 y 8. En: www.legalpublishing.cl. Cita Online: CL/JUR/1949/2012, [visitada el 25/02/2013].

106 Álvarez-Linera y Uría, César, "Efectos jurídico-procesales y materiales de la admisión de la demanda", en Efectos jurídicos del proceso (cosa juzgada. Costas e intereses. Impugnaciones y jura de cuentas), Cuadernos de Derecho Judicial, Consejo General del Poder Judicial, 1996, p. 25.

107 Álvarez-Linera y Uría, "Efectos", cit. nota n. 106, p. 28.

${ }^{108}$ Romero, La cosa juzgada, cit. nota n. 29, p. 48.
} 
310 del CPC. Sin embargo, debido a la amplitud de las hipótesis contenidas en el CPC para la procedencia de la acumulación de autos, sería posible solicitar la acumulación de los procesos idénticos objetivamente.

\section{d) Cosa juzgada}

Cuando nos referimos a cosa juzgada desde una perspectiva procesal, hablamos de dos conceptos: por una parte, de la posibilidad de ejecutar lo resuelto por un tribunal y de la irrevocabilidad del fallo jurisdiccional ${ }^{109}$. Desde la perspectiva material, ya como ficción ya como presunción de verdad, en donde no se admite prueba en contrario de lo resuelto por la resolución judicial de la que deriva ${ }^{110}$.

En nuestro Derecho, se asume en el CPC como presunción de verdad ${ }^{111}$ siguiendo las doctrinas materiales de la cosa juzgada que, en síntesis, se sustentan en que lo declarado por una sentencia judicial definitiva es verdadero.

Sin embargo, la doctrina procesal la configura como un efecto derivado de la sentencia, que no produce ninguna consecuencia sobre el derecho material que formó parte del objeto del proceso, y este efecto es precisamente la imposibilidad de revisar el mérito de la resolución dictada, ya sea en ese proceso mediante la interposición de recursos ni en otro proceso diverso.

Este efecto que tiene como consecuencia la irrevocabilidad del fallo, considera como condición esencial la firmeza de la resolución, de su ejecutoriedad, hipótesis previstas por el legislador chileno en el artículo 174 del CPC.

La justificación histórica de esta institución ha sido la misma de la litispendencia, esto es, mantener la seguridad jurídica evitando la multiplicidad de fallos entre las mismas partes sobre cuestiones que ya han sido resueltas una vez. En este sentido, es una manifestación del principio non bis in ídem en su vertiente de prohibición de reiteración de juicios como manifestación del efecto negativo de la cosa juzgada ${ }^{112}$ y prohibición de condena por un mismo hecho ${ }^{113}$.

En su vertiente procesal, este principio supone la prohibición de un doble enjuiciamiento por los mismos hechos que vulneren el mismo bien jurídico en base a un mismo fundamento ${ }^{114}$.

\footnotetext{
${ }^{109}$ Pereira, La cosa juzgada, cit. nota n. 72, p. 43; p. 48.

110 Pereira, La cosa juzgada, cit. nota n. 72, pp. 32-33; más modernamente, Romero Seguel, Alejandro, "La sentencia judicial como medio de prueba", Revista Chilena de Derecho, vol. 39, № 2, 2012, pp. 253-254.

111 Romero, La cosa juzgada, cit. nota n. 29, p. 14.

112 Romero, La cosa juzgada, cit. nota n. 29, p. 11; p. 49.

${ }^{113}$ Cano, "Non bis in ídem", cit. nota n. 30, p. 191.

${ }^{114}$ CANO, "Non bis in ídem", cit. nota n. 30, p. 198.
} 
La prohibición de enjuiciar varias veces los mismos hechos no sólo garantiza los principios de seguridad jurídica, interdicción de la arbitrariedad y proporcionalidad, sino que evita, además, la posibilidad de una doble sanción o que recaigan eventuales pronunciamientos de un signo contradictorio ${ }^{115}$.

Se ha planteado que el non bis in ídem es el fundamento del efecto negativo o función excluyente de la cosa juzgada material, ya que ésta última no es otra cosa que el instrumento procesal para garantizar la prohibición de un nuevo enjuiciamiento sobre los mismos hechos y el mismo fundamento ${ }^{116}$.

Dentro de nuestra doctrina procesal tradicional, se ha definido la cosa juzgada como "el efecto de las sentencias definitivas o interlocutorias firmes o ejecutoriadas, para que aquel a cuyo favor se ha declarado un derecho en el juicio pueda pedir el cumplimiento o ejecución de los resuelto y para que el litigante que haya obtenido en él, o todos aquellos a quiénes según la ley aprovecha el fallo, impidan que la cuestión fallada en un juicio, sea nuevamente resuelta en el ese o en otro juicio"117.

Por su parte, Liebman plantea que la sentencia como cualquier acto procesal tiene firmeza desde que no es posible realizar otros actos dentro del proceso en que fue dictada para modificarla, sin embargo, la cosa juzgada es una "nueva y particular fuerza" que la desvincula de los actos del procedimiento, asegurando su duración en el tiempo haciendo indiscutible e incondicionada su eficacia ${ }^{118}$.

Más modernamente, Nieva ha restado importancia a la cosa juzgada como efecto, señalando que no es más que una prohibición de reiteración de juicios, tal como fue configurada ya desde el Código de Hammurabi ${ }^{119}$.

Se ha establecido desde antiguo que la cosa juzgada cubre lo efectivamente discutido y sentenciado en juicio ${ }^{120}$, lo que es denominado en doctrina como los límites objetivos de la cosa juzgada. Y ello, sin duda, tiene relación con las acciones y excepciones promovidas por las partes durante la fase de discusión, ya que el juez en virtud de la congruencia del fallo, manifestación del principio dispositivo que rige el proceso civil, deberá pronunciarse respecto de dichas alegaciones $^{121}$. Lo anterior se manifiesta en el artículo 170 número 3 del CPC, que

\footnotetext{
${ }^{115}$ Cano, "Non bis in ídem", cit. nota n. 30, p. 200.

${ }^{116}$ De la Oliva, De la cosa juzgada, cit. nota n. 73, p. 25.

117 Pereira, La cosa juzgada, cit. nota n. 72, p. 34.

118 LieBMAN, Manual, cit. nota n. 59, pp. 590-591.

119 Nieva Fenoll, Jordi, La cosa juzgada. El fin de un mito, Abeledo Perrot-LegalPublishing, Santiago, 2010, pp. 30-33.

120 Pereira, La cosa juzgada, cit. nota n. 72, p. 52.

${ }^{121}$ Escusol Barra, Eladio, La incongruencia de la sentencia. Su análisis como motivo de casación en la jurisdicción civil y en la contencioso-administrativa, Colex, Madrid, 1998, p. 38.
} 
señala como requisito de toda sentencia definitiva de primera o única instancia el pronunciamiento respecto de todas las acciones y excepciones promovidas en el proceso.

La jurisprudencia ha señalado al respecto que "las consideraciones que sirven de fundamento inmediato de la parte resolutiva de la sentencia, son elementos que deben tomarse en cuenta para la declaración sobre la cosa juzgada"122.

La existencia de un pronunciamiento sobre las acciones y excepciones opuestas supone una resolución sobre el fondo del asunto que fue objeto principal del juicio, sin que las resoluciones denominadas absolutorias de la instancia, esto es, las que se pronuncian sobre la concurrencia de cuestiones procesales, produzcan este efecto ${ }^{123}$. Sin embargo, la jurisprudencia de la Corte Suprema ha fallado que la resolución que desecha la excepción de incompetencia, siendo una sentencia interlocutoria produce cosa juzgada ${ }^{124}$.

En relación con la problemática de la concurrencia, será relevante la determinación de lo que efectivamente fue objeto procesal del juicio en donde se dictó la sentencia que se invoca como antecedente de la excepción de cosa juzgada -lo que devino en firme-, ya que de ello dependerá el juicio comparativo que se debe realizar respecto del objeto procesal del nuevo juicio.

Si estamos en presencia de un concurso de normas, el objeto procesal del primer juicio es idéntico al del segundo, ya que un cambio en la calificación jurídica de los hechos esgrimidos no constituye una nueva acción. Por el contrario, si lo que se produce es un concurso de acciones, estamos ante objetos procesales diversos y la cosa juzgada no puede prosperar como excepción en el segundo juicio.

En este sentido, al igual que en el análisis efectuado para la procedencia de la litispendencia, se debe producir en el caso concreto la identidad total de los elementos de las acciones deducidas en uno y en otro juicio para que sea procedente la cosa juzgada.

Sin embargo, eventualmente es posible que el objeto procesal del primer juicio sea parcialmente idéntico y no totalmente, caso en el cual la eficacia de la

\footnotetext{
${ }^{122}$ En este sentido, Novoa con Del Campo, Corte Suprema, casación en la forma civil, 02 de septiembre de 1916, RDJ, T. XIV, Parte 1'a, Sec. 1ª, 1917, p. 170; Wehrhahn con Sociedad Ganadera Gente Grande, Corte Suprema, casación en la forma civil, 30 de octubre de 1928, RDJ, T. XXVII, Parte $1^{\text {a }}$, Sec. $1^{\text {a }}$, 1930, pp. 14-15; Romo con Cuadra, Corte de Apelaciones de Santiago, recurso de apelación civil, 29 de agosto de 1933, RDJ, T. XXXI, parte $2^{\text {a }}$, Sec. $2^{\text {a }}$, 1934, p. 61.

${ }^{123}$ Romero, La cosa juzgada, cit. nota n. 29, p. 22.

${ }^{124}$ En este sentido, Moro con Asociación de Productores de Yodo de Chile, Corte Suprema, casación en la forma civil, 21 de noviembre de 1933, RDJ, T. XXXII, Parte 2a ${ }^{a}$, Sec. 1ª, 1935, p. 169; Jackson Hill, Hugo con Fisco, Corte Suprema, Casación en la forma civil, 10 de agosto de 1948, RDJ, T. XLV, Parte 2a , Sec. 1ª 1948, p. 689; Molina vda. de Rosales, María con Compañía Sudamericana de Vapores, Corte Suprema, casación civil, 01 de abril de 1950, RDJ, 1950, T. XLVII, Parte 1ª, Sec. 1ª, p. 109.
} 
sentencia dictada es positiva o prejudicial en el segundo juicio, por la conexión objetiva o subjetiva de las acciones deducidas en ambos procesos.

Se ha manifestado por la doctrina que un asunto es prejudicial a otro cuando ambos son independientes, esto es, cuando los objetos de ambos asuntos no son idénticos, debiendo ambos tener la entidad suficiente para ser tramitados como procesos autónomos ${ }^{125}$. Por su parte, en cuanto al contenido de las resoluciones dictadas en ambos procesos, la prejudicialidad de la resolución dictada en uno de ellos establece la necesidad de que el juez del segundo proceso deba respetar como firme lo fallado por el otro, puesto que dichas cuestiones constituyen un antecedente lógico de la segunda decisión ${ }^{126}$. En otras palabras, la sentencia dictada en un primer proceso que tiene un objeto parcialmente idéntico a un segundo, obliga al juez del segundo proceso, quien se verá limitado en su decisión al contenido del primer fallo, tomándolo como indiscutible punto de partida ${ }^{127}$.

En nuestro Derecho sólo están reguladas las cuestiones prejudiciales civiles respecto de un proceso penal y viceversa en los artículos 179 y 180 del CPC; 173 y 174 del COT. Reconociendo esta institución resolvió la Corte de Apelaciones de Valparaíso, atribuyendo la cosa juzgada a una sentencia dictada por un juzgado de Policía Local en una causa civil substanciada con posterioridad, aunque por razones que no compartimos ${ }^{128}$. También lo hace la Corte Suprema en un fallo en donde establece que el juez árbitro que resolvía sobre un juicio particional sobre liquidación social "con sujeción estricta a las declaraciones hechas en la sentencia que trataba de ejecutarse, ya que ellas revestían para el árbitro la autoridad de la cosa juzgada, y no podía contrariarlas sin afectar de nulidad su fallo"129.

\footnotetext{
${ }^{125}$ Reynal Querol, Núria, La prejudicialidad en el proceso civil, Bosch, Barcelona, 2006, p. 32.

${ }^{126}$ Calamandrel, Instituciones, cit. nota n. 101, p. 302.

127 De la Oliva, De la cosa juzgada, cit. nota n. 73, p. 25.

128 "Que la sentencia firme dictada en el juicio de policía local, (...) produce cosa juzgada en sede civil en virtud de lo dispuesto en el artículo 179 del Código de Procedimiento Civil, con prescindencia de si se ha reunido o no la triple identidad que establece el artículo 177 del mismo Código, pues como ha señalado la jurisprudencia y la doctrina, la cosa juzgada de la sentencia dictada en sede criminal produce efectos erga omnes, pues se trata de un efecto de cosa juzgada que se aleja de los principios generales aceptados en la materia, desde el momento que el objeto de la acción civil es materialmente diferente al de la acción penal y no obstante ello lo resuelto en esta última sede produce efectos en materia civil". La eficacia que produce la sentencia no lo es como hecho jurídico -erga omnes-, sino más bien por la conexión de los objetos procesales de ambos juicios. Tapia con Fundación Corporación The Mackay School, Corte de Apelaciones de Valparaíso, Recurso de apelación juzgado de policía local, 20 de diciembre de 2012, Rol № 613-2012, c. 5. En: www.legalpublishing.cl. Cita Online: CL/ JUR/2937/2012, [visitada el 25/02/2013].

${ }^{129}$ Contreras con Coudeu, Corte Suprema, casación en el fondo civil, 08 de junio de 1906, RDJ, T. III, $2^{\circ}$ parte, Sec. $1^{\text {a }}, 1905-1906$, p. 387.
} 
Lo dicho hasta aquí, parte de la base de un fallo firme que produce cosa juzgada material. Sin embargo, no todas las sentencias definitivas producen este efecto, ya que hay resoluciones que sin perjuicio de no poder ser revisadas en el juicio en que se dictaron, sí pueden serlo en otro proceso posterior ${ }^{130}$.

El legislador, en estos casos, ha previsto que las sentencias dictadas en ciertos tipos de procesos o a propósito de situaciones fácticas que pueden ser objeto de modificaciones ${ }^{131}$ no produzcan irrevocabilidad.

Ciertos tipos de procesos como algunas tutelas de urgencia, como lo es el recurso de protección ${ }^{132}$ y procedimientos de carácter ejecutivo, suponen limitaciones procedimentales en las posibilidades de las partes para el ejercicio de su derecho de defensa. En estos casos se señala que el objeto procesal que originó la dictación del primer fallo puede ser objeto de nuevos procesos o las partes pueden reservarse sus acciones y excepciones para un proceso posterior ${ }^{133}$. En este sentido, Pereira ${ }^{134}$.

De este modo, es discutible que una sentencia dictada en un procedimiento que no cumple con los estándares mínimos del debido proceso produzca cosa juzgada material, posibilitándose la reapertura de la discusión en un proceso posterior.

En el otro caso señalado, la naturaleza de la relación jurídica sustancial determina que el objeto procesal discutido en un proceso anterior, pueda volver a serlo en un nuevo proceso, amparado en el hecho que las circunstancias fácticas del debate han sido modificadas. En este sentido, podríamos decir que lo que ocurre es más bien un cambio del objeto procesal debido al factor tiempo que determina que la relación jurídica sustancial no es exactamente la misma en ambos procesos ${ }^{135}$. Casos en nuestro ordenamiento son las demandas por alimentos, cuidado personal, relación directa y regular en materia de Derecho de familia. En sentencias antiguas, se manifiesta expresamente que las resoluciones dictadas en estas materias, no tiene cabida la cosa juzgada, refiriéndose a la cosa

\footnotetext{
130 "De ahí que la cosa juzgada formal sólo produce efectos en el proceso en que se dictó la sentencia firme y nada más que en él; la cosa juzgada material o substancial, en cambio, adquiere valor especialmente para procesos futuros con el objeto de impedir un nuevo pronunciamiento sobre el asunto ya fallado. Sintetizando, la primera es eficaz dentro del proceso en que el fallo firme se dictó; la segunda, normalmente, fuera de ese proceso". Pereira, La cosa juzgada, cit. nota n. 72, p. 76.

${ }^{131}$ Romero, La cosa juzgada, cit. nota n. 29, pp. 30-34.

132 Sobre las limitaciones a nivel procesal que constituye la acción de protección y la eficacia de la sentencia dictada en dicho proceso, confróntese Romero Seguel, Alejandro, "Notas sobre la cosa juzgada en el recurso de protección", Revista Chilena de Derecho, vol. 26, № 2, 1999, pp. 503-515.

${ }^{133}$ Artículo 478, Ley No 1.552, Aprueba el Código, cit. nota n. 21.

${ }^{134}$ Pereira, La cosa juzgada, cit. nota n. 72, p. 84.

${ }^{135}$ Berzosa, Demanda, cit. nota n. 7, pp. 43-46.
} 
juzgada material ${ }^{136}$. En estos casos, la acción no se considera la misma, ya que el factor temporal del objeto procesal ha modificado las circunstancias fácticas que se tuvieron en consideración a la hora de resolver el primer proceso, por lo que, a nuestro juicio, se produce un concurso de acciones.

\section{CONCLusiones}

1. La concurrencia es un fenómeno común a todas las disciplinas jurídicas, que se basa en la existencia de un supuesto de hecho que se puede subsumir en dos o más normas jurídicas.

2. La concurrencia es causada esencialmente por la creación por parte del legislador de acciones destinadas a ser vehículo de una mejor protección de los derechos e intereses de particulares mediante tutelas diferenciadas y especiales.

3. En la mayoría de los casos, el legislador no ha previsto cómo deben solucionarse los conflictos procesales derivados de la concurrencia de dos o más acciones o normas en la solución de un conflicto de intereses y/o en la dictación de un fallo por parte de los tribunales.

4. La compatibilidad o incompatibilidad de mecanismos de protección se determina analizando las acciones a deducir mediante una comparación de sus elementos objetivos: causa de pedir y petición, sin que la calificación jurídica efectuada por el actor constituya parte del fundamento de la acción deducida.

5. Si las acciones son distintas existe un concurso de acciones, el que deberá ser resuelto posibilitando la interposición de todas las acciones concurrentes por configurar cada una de ellas un objeto procesal diverso, sin que quepa la modificación de la acción durante el proceso y sin que sean susceptibles de acogerse las excepciones de litispendencia y cosa juzgada eventualmente alegables en base a procesos pendientes o terminados iniciados en base a la acción concurrente.

6. Si la acción es una sola, y el efecto jurídico está doblemente garantizado en el ordenamiento jurídico, el concurso es de normas, produciéndose el efecto procesal inverso al caso anterior, pudiéndose hacer calificaciones jurídicas diversas durante el proceso, ya que ello no produce una modificación de la acción deducida, y es procedente acoger las excepciones de litispendencia o cosa juzgada en base a la existencia de un proceso pendiente en donde se invocó la misma acción o uno terminado con sentencia firme.

${ }^{136}$ En este sentido, Noguera con Vega, Corte Suprema, casación en la forma, 03 de noviembre de 1937, RDJ, 1938, T. XXXV, Parte 1ª, Sec. $1^{\text {a }}$, p. 172; Duarte con Olivares, Corte Suprema, casación fondo, 23 de mayo de 1946, RDJ, T. XLIV, Sec. 1a, 1947, p. 231; Larrazábal de De la Sotta, Nora con De la Sotta, Juan, Corte Suprema, casación fondo, 17 de marzo de 1949, RDJ, T. XLVI, Parte 1ª, Sec. $1^{\text {a }}, 1949$, p. 398. 


\section{Bibliografía CitADA}

\section{1) Libros}

AlesSANDrI Rodríguez, Arturo, De la responsabilidad extracontractual en el Derecho civil chileno, Editorial Jurídica de Chile, Santiago, 2005, 559 pp.

Alonso Traviesa, María Teresa, El problema de la concurrencia de responsabilidades, LegalPublishing, Fundación Fueyo, Santiago, 2007, 583 pp.

Armenta Deu, Teresa, La acumulación de autos, Editorial Montecorvo S.A., Madrid, 1997, 309 pp.

Baptista DA SILVA, Ovidio, Teoría de la acción cautelar, Antonio Fabris Editor, Porto Alegre, 1993, $127 \mathrm{pp}$.

Barros Bourie, Enrique, Tratado de responsabilidad extracontractual, Editorial Jurídica de Chile, Santiago, 2009, 1230 pp.

Bellido Penadés, Rafael, La tutela frente a la competencia desleal en el proceso civil, Comares, Granada, 1998, 430 pp.

Berzosa Francos, María Victoria, Demanda, "causa petendi", y objeto del proceso, El Almendro, Córdoba, 1984, 239 pp.

Botto OAkley, Hugo, La incongruencia procesal, Córdoba, Lerner, 2006, pp. 260.

Calamandrel, Piero, Instituciones de Derecho procesal civil, El Foro, Buenos Aires, t. I, 1996, 421 pp.

Chiovenda, Giuseppe, Principios de Derecho procesal civil, REUS, Madrid, t. I, 1977, 767 pp.

CoRRAl TalCiani, Hernán, Lecciones de responsabilidad civil extracontractual, Editorial Jurídica de Chile, Santiago, 2003, 423 pp.

De la Oliva Santos, Andrés, De la cosa juzgada (civil, contencioso-administrativa y penal, con examen de jurisprudencia del Tribunal Constitucional), Editorial Centro de Estudios Ramón Areces S.A., Madrid, 1991, 196 pp.

, Objeto del proceso y cosa juzgada en el proceso civil, Thompson Civitas, Madrid, 2005, 292 pp.

De la Oliva Santos, Andrés; Díez-Picazo Giménez, Ignacio, Derecho procesal civil. El proceso de declaración, Editorial universitaria Ramón Areces, Madrid, 2004, 681 pp.

Domínguez Hidalgo, Carmen, El Daño Moral, Editorial Jurídica de Chile, Santiago, 2000, Dos Tomos, 782 pp.

Escusol BARRA, Eladio, La incongruencia de la sentencia. Su análisis como motivo de casación en la jurisdicción civil y en la contencioso-administrativa, Colex, Madrid, 1998, 180 pp.

EtcheberRy Orthusteguy, Alfredo, El concurso aparente de leyes penales, Editorial Jurídica de Chile, Santiago, S/A, 108 pp. 
Fairén Guillén, Víctor, La transformación de la demanda en el proceso civil, Porto, Santiago de Compostela, 1949, 159 pp.

González Navarro, Francisco, Derecho administrativo español, EUNSA, Pamplona, 1995, $1242 \mathrm{pp}$.

Guzmán Brito, Alejandro, La fijación del Derecho. Contribución al estudio de su concepto y de sus clases y condiciones, Ediciones Universitarias de Valparaíso, Valparaíso, 1977, 128 pp.

IRTI, Natalino, La edad de la descodificación, Bosch, Barcelona, 1992, 214 pp.

Larenz, Karl, Metodología de la ciencia del Derecho, Ariel, Barcelona, 2001, $536 \mathrm{pp}$.

Liebman, Enrico Tullio, Manual de Derecho Procesal Civil, EJEA, Buenos Aires, 1980, 725 pp.

Matus Acuña, Jean Pierre, El concurso aparente de leyes, Ediciones Jurídicas de Santiago, Santiago, 2008, 430 pp.

Montero Aroca, Juan y otros, Derecho jurisdiccional I, Parte General, Tirant lo Blanch, Valencia, 2007, 494 pp.

Murga, José Luis, Derecho romano clásico. II. El Proceso, Secretariado de Publicaciones Universidad de Zaragoza, Zaragoza, 1989, 413 pp.

Nieva Fenoll, Jordi, La cosa juzgada. El fin de un mito, Abeledo Perrot LegalPublishing, Santiago, 2010, 88 pp.

Ormazábal Sánchez, Guillermo, lura novit curia. La vinculación del juez a la calificación jurídica de la demanda, Marcial Pons, Madrid, 2007, 135 pp.

Pereira Anabalón, Hugo, La cosa juzgada formal en el procedimiento civil chileno, Editorial Jurídica de Chile, Santiago, 1954, 222 pp.

Pıcó I Junor, Joan, La buena fe procesal, Depalma, Ibáñez, Pontificia Universidad Javeriana, Bogotá, 2011, 148 pp.

Prieto-Castro y Ferrándiz, Leonardo (1985), Tratado de Derecho Procesal Civil. Proceso declarativo. Proceso de ejecución, Editorial Aranzadi, Pamplona, t. I, 908 pp.

Reynal Querol, Núria, La prejudicialidad en el proceso civil, Bosch, Barcelona, 2006, 564 pp.

Robles Reyes, Juan, La competencia jurisdiccional y judicial en Roma, Servicio de Publicaciones de la Universidad de Murcia, Murcia, 2003, 182 pp.

Romero Seguel, Alejandro, La acumulación inicial de acciones (artículos 17 y 18 del Código de Procedimiento Civil), Editorial Jurídica ConoSur Ltda., Santiago, 2000, 159 pp.

, La cosa juzgada en el proceso civil chileno. Doctrina y jurisprudencia, Editorial Jurídica de Chile, Santiago, 2002, 157 pp. 
, Curso de Derecho procesal civil. La acción y la protección de los derechos, Editorial Jurídica de Chile, Santiago, t. I., 2006, 128 pp.

, Curso de Derecho procesal civil. Los presupuestos procesales relativos al órgano jurisdiccional, Editorial Jurídica de Chile, Santiago, t. II, 2009, $91 \mathrm{pp}$.

SCHwab, Karl Heinz, El objeto litigioso en el proceso civil, EJEA, Buenos Aires, 1968, 301 pp.

TAPIA FERNÁNDEZ, Isabel, La reconvención. Límites. Jurisprudencia, Editorial General de Derecho S.L., Valencia, 1994, 143 pp.

El objeto del proceso. Alegaciones. Sentencia. Cosa Juzgada, La Ley, Madrid, 2000, 239 pp.

Yzquierdo Tolsada, Mariano, Sistema de responsabilidad civil contractual y extracontractual, Dykinson, Madrid, 2001, 545 pp.

\section{2) Artículos en publicaciones seriadas}

Álvarez-Linera y Uría, César, "Efectos jurídico-procesales y materiales de la admisión de la demanda", en Efectos jurídicos del proceso (cosa juzgada. Costas e intereses. Impugnaciones y jura de cuentas), Cuadernos de Derecho Judicial, Consejo General del Poder Judicial, 1996, pp. 11-66.

Barrientos Camus, Francisca, "El vicio de la cosa comprada. La noción de vicio redhibitorio en el régimen de saneamiento del Código Civil y la Ley sobre protección de los derechos de los consumidores", en De LA MAZA, Íñigo (coord.) Incumplimiento contractual. Nuevas perspectivas, Cuadernos de Análisis Jurídico, Colección Derecho privado VII, Ediciones Universidad Diego Portales, Facultad de Derecho, 2011, pp. 363-385.

Bordalí Salamanca, Andrés, "Análisis crítico de la jurisprudencia del Tribunal Constitucional sobre el derecho a la tutela judicial", Revista Chilena de Derecho, vol. 38, № 2, 2011, pp. 311-337.

Bravo LiRA, Bernardino, "Los comienzos de la codificación en Chile: la codificación procesal", Revista Chilena de Historia del Derecho, № 9, 1983, pp. 191-210.

Cano Campos, Tomás, "Non bis in ídem, prevalencia de la vía penal y teoría de los concursos en el Derecho administrativo sancionador", Revista de Administración Pública, № 156, 2001, pp. 191-249.

De la Maza Gazmurı, Íñigo, "El régimen de los cumplimientos defectuosos en la compraventa", Revista Chilena de Derecho, vol. 39, № 3, 2012, pp. 629663.

González Vergara, Paulina, "Codificación y técnica legislativa", Revista Chilena de Derecho, vol. 25, № 4, 1998, pp. 867-895. 
GuasP, Jaime, "La pretensión procesal", Anuario de Derecho Civil, Madrid, Instituto Nacional de Estudios Jurídicos, Madrid, 1952, pp. 7-61.

GutiérRez de Cabiedes, Víctor, "La litis-pendencia", Revista de Derecho procesal iberoamericana, № 3, 1969, p. 605-652.

GuZmán BRITo, Alejandro, "Historia de la denominación del derecho-facultad como subjetivo", Revista de estudios histórico-jurídicos, № XXV, 2003, pp. 407-443.

Hercé Quemada, Vicente, "Derecho procesal civil y Derecho civil: su delimitación", Boletín mexicano de Derecho comparado, № 24, 1975, pp. 577594.

Hunter Ampuero, Iván, "Iura novit curia en la jurisprudencia civil chilena", Revista de Derecho, Universidad Austral de Chile, vol. XXIII, No 2, 2010, pp. 197-221.

Megías, José (2003) "El derecho subjetivo en el Derecho romano", Revista de estudios histórico-jurídicos, N XXV, 2003. En: http://www.scielo.cl/scielo. php?script=sci_arttext\&pid=S0716-5455203002500002\&Ing=es\&nrm=iso \&tlng=es [visitado el 12/04/2012].

Palomo Vélez, Diego, "Apelación, doble instancia y proceso civil oral", Estudios constitucionales, año VIII, No 2, 2010, pp. 465-524.

Pérez Bravo, Carlos, "Concurrencia de responsabilidades", Ars Boni et Aequi, № 4, 2008, pp. 111-125.

Prieto-Castro y Ferrándiz, Leonardo, "El cambio del punto de vista jurídico", Revista de Derecho Procesal, publicación iberoamericana y filipina, $N^{\circ} 1$, 1956, pp. 3-25.

Romero Seguel, Alejandro, "Notas sobre la cosa juzgada en el recurso de protección", Revista Chilena de Derecho, vol. 26, № 2, 1999, pp. 503-515.

"La sentencia judicial como medio de prueba", Revista Chilena de Derecho, vol. 39, № 2, 2012, pp. 251-276.

, "La adecuación del procedimiento en materia de derecho indígena", Revista Chilena de Derecho, vol. 39, № 3, 2012, pp. 819-828.

Serra Domínguez, Manuel, "Litispendencia", Revista de Derecho Procesal Iberoamericana, $N^{\circ} 3,1969$, pp. 653-682.

Vargas Pavez, Macarena, "Reflexiones en torno a los alcances del fenómeno descodificador en el proceso civil", Revista Chilena de Derecho Privado, $\mathrm{N}^{\circ}$ 17, 2011, pp. 9-26.

VIDAL Olivares, Álvaro, "Las acciones emanadas del daño ambiental y el régimen de responsabilidad aplicable", en PIZARro WILSON, Carlos (dir.) Regímenes especiales de responsabilidad civil, Cuadernos de Análisis Jurídico, Colección de Derecho Privado IV, Ediciones Universidad Diego Portales, 2008, pp. 191-210. 
, "El incumplimiento y los remedios del acreedor en la propuesta de modernización del derecho de las obligaciones y contratos español", Revista Chilena de Derecho Privado, № 16, 2011, pp. 243-302.

\section{3) Artículos en libros o capítulos de libros}

CAPRILE, Bruno, "Las acciones del comprador insatisfecho: el cúmulo actual (ley de protección al consumidor, vicios redhibitorios. Error sustancial, resolución por incumplimiento) y la tendencia al deber de conformidad en el Derecho Comparado", en MANTILLA, Fabricio y otro (coord.) Estudios de Derecho privado en homenaje a Christian Larroumet, Fundación Fueyo Universidad Diego Portales, Universidad del Rosario, Santiago, 2008, pp. 561-602.

Fairén Guillén, Víctor, "La 'litis contestatio' y sus consecuencias: una perspectiva histórica del proceso" en Estudios de Derecho procesal, Editorial Revista de Derecho Privado, Madrid, 1955, pp. 13-57.

FerRada Bórquez, Juan Carlos, "Los tribunales que ejercen la justicia administrativa en el Derecho chileno", en Litigación Pública, Colección de Estudios de Derecho Público, Abeledo Perrot, Thompson Reuters, Santiago, 2011, pp. 119-150; particularmente pp. 119-150.

Gómez Orbaneja, Emilio, "Concurso de leyes y concurso de acciones en el Derecho civil", en Derecho y Proceso, Civitas Thompson-Reuters, Pamplona, 2009, pp. 153-166.

LARA ARroyo, José Luis, "Algunas reflexiones sobre el contencioso administrativo en Chile", en Litigación Pública, Colección Estudios de Derecho Público, LegalPublishing, Abeledo Perrot, Thompson Reuters, Santiago, 2011, pp. 65-92.

LieBman, Tullio Enrico, "Acciones concurrentes", en Eficacia y autoridad de la sentencia y otros estudios sobre la cosa juzgada, EDIAR, Buenos Aires, 1946, pp. 243-258.

Martín Casals, Miguel, "Preámbulo y disposiciones directivas", en La forma de las leyes. Diez estudios de técnica legislativa, Bosch, Barcelona, 1986, pp. 59-92.

PIZARRO WILSON, Carlos, "La responsabilidad por daño ambiental en perspectiva civil", en Mantilla, Fabricio y otro (coord.) Estudios de Derecho privado en homenaje a Christian Larroumet, Fundación Fueyo Universidad Diego Portales, Universidad del Rosario, Santiago, 2008, pp. 387-400.

ViVer I PI-SunYer, Carles, "La parte final de las leyes", en La forma de las leyes. Diez estudios de técnica legislativa, Barcelona, Bosch, 1986, pp. 127-195.

WINDSCHEID, Bernhard, "La 'actio' del Derecho civil romano desde el punto de vista del Derecho actual", en Polémica sobre la "actio", EJEA, Buenos Aires, 1974, pp. 1-196. 


\section{4) Sentencias}

Asesorías e Inversiones Osbon Limitada contra Pérez, Corte de Apelaciones de Talca, recurso de apelación civil, 13 de octubre de 2010, Rol № 465-2010, c. 6. En: www.legalpublishing.cl. Cita Westlaw Chile: CL/JUR/8284/2010, [visitada el 20/01/2012].

Benavente con Junta de Beneficencia de Concepción, Corte Suprema, casación en la forma civil, 12 de noviembre de 1904, RDJ, T. III, Parte $2^{a}$, Sec. $1^{\text {a }}$, 1905-1906, p. 374.

Binimelis y otros con Servicio de Evaluación Ambiental, Corte de Apelaciones de Santiago, acción de protección, 28 de mayo de 2013, Rol № 26.9942013. En: http://corte.Poderjudicial.cl/SITCO RTEPORWEB/ [visitada el 05/07/2013].

Contreras con Coudeu, Corte Suprema, casación en el fondo civil, 08 de junio de 1906, RDJ, T. III. $2^{\text {a }}$ parte, Sec. 1'a, 1905-1906, p. 387.

Duarte con Olivares, Corte Suprema, casación fondo, 23 de mayo de 1946, RDJ, T. XLIV, Sec. 1a, 1947, pp. 225-234.

Equifax Chile S.A. con Millas, Corte de Apelaciones de Santiago, recurso de casación en la forma y apelación civil, 30 de agosto de 2012, Rol № 16972012, c. 7 y 8. En: www.legalpublishing.cl. Cita Online: CL/JUR/1949/2012, [visitada el 25/02/2013].

Jackson Hill, Hugo con Fisco, Corte Suprema, casación en la forma civil, 10 de agosto de 1948, RDJ, T. XLV, Parte 2 ${ }^{a}$, Sec. 1ª, 1948, pp. 686-690.

Larrazabal de De la Sotta, Nora con De la Sotta, Juan, Corte Suprema, casación fondo, 17 de marzo de 1949, RDJ, T. XLVI, Parte $1^{\text {a }}$, Sec. $1^{\text {a }}$, 1949, pp. 396398.

Maldonado con Inmobiliaria y Constructora El Solar de Peñuelas, Tercer Juzgado de Letras de Coquimbo, Procedimiento ordinario civil sobre resolución de contrato con indemnización de perjuicios, 29 de mayo de 2012 Rol № 10092011, c. 7. En: http://civil.poderjudicial.cl/CIVILPORWEB/?opc_menu=7, [visitada el 31/07/2013].

Matamala con Moya, Corte de Apelaciones de Santiago, recurso de apelación civil, 24 de mayo de 2010, Rol No 2714-2009, c. 2. En: www.legalpublishing. cl. Cita Westlaw Chile: CL/JUR/2954/2010 [visitada el 20/01/2012].

Molina vda. de Rosales, María con Compañía Sudamericana de Vapores, Corte Suprema, casación civil, 01 de abril de 1950, RDJ, T. XLVII, Parte 1a, Sec. 1a, 1950, pp. 105-109.

Moro con Asociación de Productores de Yodo de Chile, Corte Suprema, casación en la forma civil, 21 de noviembre de 1933, RDJ, T. XXXII, Parte $2^{a}$, Sec. $1^{\text {a }}$, 1935, pp. 167-169. 
Noguera con Vega, Corte Suprema, 03 de noviembre de 1937 (casación forma), RDJ, 1938, T. 35, Parte $1^{\text {a }}$, Sec. $1^{\text {a }}$, pp. 170-173.

Novoa con Del Campo, Corte Suprema, casación en la forma civil, 02 de septiembre de 1916, RDJ, T. XIV, Parte 1' ${ }^{\text {, }}$ Sec. 1 ${ }^{\text {a }}$, 1917, pp. 166-171.

Romo con Cuadra, Corte de Apelaciones de Santiago, recurso de apelación civil, 29 de agosto de 1933, RDJ, T. XXXI, parte $2^{\text {a, }}$ Sec. $2^{\circ}$, 1934, pp. 59-62.

Salinas con Servicio de Impuestos Internos, Tribunal Constitucional, requerimiento de inaplicabilidad por inconstitucionalidad, 6 de septiembre de 2007, Rol No 616, c. 17. En: http://www.tribunalconstitucional.cl/wp/expedientes [visitada el 29/07/2013].

Sindicato Empresa Minera Lolol actual Tambillos con Sociedad Contractual Minera Tambillos, Corte de Apelaciones de La Serena, recurso de nulidad laboral, 25 de noviembre de 2009, Rol T № 113-2009, c. 10. En: www.poderjudicial.cl [visitada el 27/11/2011].

Tapia con Fundación Corporación The Mackay School, Corte de Apelaciones de Valparaíso, Recurso de apelación juzgado de policía local, 20 de diciembre de 2012, Rol No 613-2012, c. 5. En: www.legalpublishing.cl. Cita Online: CL/JUR/2937/2012, [visitada el 25/02/2013].

Wehrhahn con Sociedad Ganadera Gente Grande, Corte Suprema, casación en la forma civil, 30 de octubre de 1928, RDJ, T. XXVII, Parte 1 ${ }^{\text {a }}$, Sec. $1^{\text {a }}$, 1930, pp. 10-15. 